\title{
Resistance to amitraz in the parasitic honey bee mite Varroa destructor is associated with mutations in the $\beta$-adrenergic-like octopamine receptor
}

\author{
Carmen Sara Hernández-Rodríguez ${ }^{1}$ (1) - Sara Moreno-Martí ${ }^{1} \cdot$ Gabrielle Almecija ${ }^{2,3}$ (i) $\cdot$ Krisztina Christmon $^{4}$. \\ Josephine D. Johnson $^{5} \cdot$ Marie Ventelon $^{6}$. Dennis vanEngelsdorp ${ }^{4} \cdot$ Steven C. Cook ${ }^{5}$. Joel González-Cabrera ${ }^{1}$
}

Received: 6 August 2021 / Revised: 19 November 2021 / Accepted: 9 December 2021 / Published online: 23 December 2021

(c) The Author(s) 2021

\begin{abstract}
Varroa destructor is considered a major reason for high loss rate of Western honey bee (Apis mellifera) colonies. To prevent colony losses caused by $V$. destructor, it is necessary to actively manage the mite population. Beekeepers, particularly commercial beekeepers, have few alternative treatments other than synthetic acaricides to control the parasite, resulting in intensive treatment regimens that led to the evolution of resistance in mite populations. To investigate the mechanism of the resistance to amitraz detected in $V$. destructor mites from French and U.S. apiaries, we identified and characterized octopamine and tyramine receptors (the known targets of amitraz) in this species. The comparison of sequences obtained from mites collected from different apiaries with different treatment regimens, showed that the amino acid substitutions N87S or $\mathrm{Y} 215 \mathrm{H}$ in the Oct $\beta \mathrm{R}$ were associated with treatment failures reported in French or U.S. apiaries, respectively. Based on our findings, we have developed and tested two high throughput diagnostic assays based on TaqMan technology able to accurately detect mites carrying the mutations in this receptor. This valuable information may be of help for beekeepers when selecting the most suitable acaricide to manage $V$. destructor.
\end{abstract}

Keywords Varroa mite $\cdot$ Acaricides $\cdot$ Target-site resistance $\cdot$ Pollinators $\cdot$ Honey bee

\section{Key message}

Carmen Sara Hernández-Rodríguez

sara.hernandez@uv.es

Joel González-Cabrera

joel.gonzalez@uv.es

1 Instituto de Biotecnología y Biomedicina BIOTECMED, Universitat de València, Dr. Moliner 50, 46100 Burjassot, Spain

2 APINOV. Centre de Recherche et Formation Apicole, 10 rue Henri Bessemer, 17140 Lagord, France

3 Institut de Recherche sur la Biologie de l'Insecte, UMR 7621, CNRS-Université de Tours, 37200 Tours, France

4 Department of Entomology, University of Maryland, College Park, MD 20742, USA

5 USDA-ARS Bee Research Laboratory, 13300 Baltimore Ave., Bldg. 306 BARC-E, Beltsville, MD 20705, USA

6 Association for the Development of Beekeeping in Auvergne Rhônes Alpes (ADA AURA), 9 allée de Fermat, 63170 Aubière, France
- Target site modification is a major mechanism of resistance to amitraz in Varroa destructor.

- Octopamine and tyramine receptors, known targets if amitraz, have been characterised.

- Amino acid substitutions N87S and Y215H, in the Oct $\beta R$, are associated with the resistance to amitraz detected in French or U.S. apiaries, respectively.

- Genotyping assays have been designed and tested to screen populations for the presence of mutant mites.

\section{Introduction}

The ectoparasitic mite Varroa destructor (Anderson and Trueman), shifted hosts from the Eastern honeybee (Apis cerana $\mathrm{L}$.) to the Western honey bee (Apis mellifera $\mathrm{L}$.) in the late 1950's (Traynor et al. 2020). Since then, it has spread almost exclusively as clonal lineages throughout 
the world (Solignac et al. 2005). In A. cerana, V. destructor causes little damage to the colonies since the parasite's population growth is limited as mites can only reproduces in drone brood, which are only available in large numbers early in summer. In contrast, $V$. destructor successfully reproduces in both drone and worker brood of A. mellifera (Beaurepaire et al. 2015). Varroa destructor damages the host by feeding directly on the fat bodies, by vectoring viruses (Boecking and Genersch 2008; Ramsey et al. 2019) and reducing natural defences (Aronstein et al. 2012). If left unmanaged, $V$. destructor will kill the colonies within a few years (Martin et al. 1998). This mite is considered one of the major causes for seasonal colony losses of the Western honey bee (Steinhauer et al. 2018).

Beekeepers have an assortment of chemical and nonchemical methods to implement Integrated Pest Management (IPM) strategies for controlling V. destructor. Most of beekeepers use synthetic chemicals to treat their colonies, since they are easier to use and appear to be most effective and consistent at reducing losses (Rosenkranz et al. 2010; Haber et al. 2019). Globally, the most commonly registered acaricides are the pyrethroids flumethrin and tau-fluvalinate, the organophosphate coumaphos, and the formamidine amitraz. In the past, tau-fluvalinate and coumaphos have been the most widely used treatments, but now these pesticides are less effective. The intensive use of pyrethroids to control $V$. destructor since the 1980's resulted in the independent emergence of resistance to these chemicals in mite populations from Europe and North America (Milani 1995; Elzen et al. 1998; Mozes-Koch et al. 2000; Sammataro et al. 2005; Gracia-Salinas et al. 2006; Kim et al. 2009; González-Cabrera et al. 2013; González-Cabrera et al. 2016; González-Cabrera et al. 2018; Hubert et al. 2014). Coumaphos was brought to market as an alternative varroacide treatment, but overuse of this product also resulted in the evolution of resistance (Elzen and Westervelt 2002; Maggi et al. 2009, 2011). Moreover, residues of varroacides persist and accumulate in beeswax (Bonzini et al. 2011; Calatayud-Vernich et al. 2018; Traynor et al. 2020), posing a sublethal threat to honey bees (Desneux et al. 2007) and possibly maintaining the selection pressure on mite populations, so preventing resistance reversion, as already reported for pyrethroids resistance in V. destructor (Milani and Della Vedova 2002; Medici et al. 2016; González-Cabrera et al. 2018; Mitton et al. 2018).

To delay the evolution of resistance, rotation of products with different modes of action is recommended (IRAC; https://www.irac-online.org/), but the lack of effective alternatives makes chemical rotation a non-practical solution for beekeepers. As a result, beekeepers are over reliant on amitraz to control mites (Haber et al. 2019), which would select for resistant mites and it may explain consistent field reports of reduced miticidal efficacy (Elzen et al. 1999,
2000; Rodríguez-Dehaibes et al. 2005; Maggi et al. 2010; Kamler et al. 2016; Rinkevich 2020).

In $V$. destructor, the mechanism of resistance to pyrethroids is already known. It is caused by substitution of key residues within the voltage gated sodium channel (VGSC), the major target site for pyrethroids (González-Cabrera et al. 2013; González-Cabrera et al. 2016; González-Cabrera et al. 2018; Hubert et al. 2014). Regarding the resistance to coumaphos, studies carried out with other species have reported that it may be associated with either mutations in its target site, the enzyme acetylcholinesterase, duplication of the acetylcholinesterase gene, or with alterations in the expression of detoxification enzymes (Feyereisen et al. 2015). However, in $V$. destructor, the mechanism(s) involved in the resistance to coumaphos remains unclear. The downregulation of a cytochrome $\mathrm{P} 450$ involved in the activation of coumaphos have been described as associated with the resistance reported in mites collected from the Greek island of Andros (Vlogiannitis et al. 2021).

In insects and Acari, amitraz binds to the receptors of octopamine and tyramine (Kumar 2019). The octopamine (OAR) and the tyramine (TAR) receptors belong to the superfamily of G-protein coupled receptors (GPCRs). GPCRs are known to be involved in recognizing extracellular messengers, transducing signals to the cytosol, and mediating the cellular responses necessary for the normal physiological functions of organisms (Liu et al. 2021). Octopamine and tyramine receptors are classified as $\alpha$-adrenergic-like octopamine receptors (Oct $\alpha_{1}$ Rs and Oct $\alpha_{2} \mathrm{Rs}$ ), $\beta$-adrenergic-like octopamine receptors (Oct $\beta_{1} \mathrm{Rs}$, Oct $\beta_{2}$ Rs, and Oct $\beta_{3}$ Rs), and tyramine receptors (TAR1, TAR2, TAR3) (Finetti et al. 2021).

Uncovering the molecular mechanisms involved in resistance to pesticides is essential for rapid detection and for designing effective management approaches. In this study, we identified and characterized octopamine and tyramine receptors of $V$. destructor. Two amino acid substitutions in Oct $\beta_{2} \mathrm{R}$ associated with reported field treatment failures of amitraz in France and the USA were identified. Finally, two robust high throughput diagnostic assays were developed to identify $V$. destructor mites carrying these mutations in order to aid in resistance management in affected communities.

\section{Materials and methods}

\section{V. destructor samples}

Samples reporting failures after treatment with amitraz in France were collected in 2019 from five apiaries belonging to departments 38 (Isère), 42 (Loire), and 63 (Puy-deDôme). These apiaries have been treated with amitraz for 
several years in a row. Mites were collected from capped brood at the end of treatment with amitraz ( 70 days after the application of strips) and stored at $-20{ }^{\circ} \mathrm{C}$ until used for molecular analysis. Mites collected at departments 4 (Alpes-de-Haute-Provence), 26 (Drôme), and 49 (Maineet-Loire) were not treated with amitraz for at least one year before collection.

U.S. samples were collected as part of different surveys and research efforts not specifically designed for identification of the mechanism of resistance to amitraz (Table S1). Bee Informed Partnership Inc. (BIP) conducted a field trial in the fall of 2018 to test the efficacy of the product Apivar ${ }^{\circledR}$ (a.i. amitraz) to reduce $V$. destructor mite infestation in colo-

\section{Evaluation of amitraz efficacy}

Acaricide efficacy of the amitraz treatments in MM16 and J11 French apiaries were calculated according to the Guideline on veterinary medicinal products controlling Varroa destructor parasitosis in bees (EMA 2010). Amitraz strips were introduced into hives at day 1 and they were removed at day 70 . The number of mites in the inspection boards was registered every two days along the treatment. The residual number of mites was determined with a follow-up treatment using oxalic acid at day 91 and the final count of the dead mites at day 106. The treatment efficacy (E) was calculated as \% of mite reduction as follows:

$E(\%)=\frac{\text { mites dropped by treatment }(\text { day } 91)}{\text { mites dropped by treatment }+ \text { mites dropped after followup treatment }} \times 100$

nies from active commercial beekeeping operations in the USA The trial was conducted within 2 commercial beekeeping operations from 2 different geographic regions. A total of 72 colonies ( 12 colonies per yard, in 3 yards for each operation) were followed over 42 days after treatment. In each yard, half of the colonies were treated with Apivar ${ }^{\circledR}$ while the other half received a positive control product, Apilife $\operatorname{Var}^{\circledR}$ (a.i. thymol). Varroa destructor load was estimated by a lab wash of a sample of $\sim 300$ bees collected from a brood frame (Dietemann et al. 2013).

Phoretic mites from the BIP project were collected from colonies taking part in field trials conducted in Oregon and Michigan in 2018. The mites collected were those still in the colony while treatments were ongoing, and so survived at least a partial treatment exposure. Of mites from the 72-colony trial, we randomly chose mites from four colonies being treated with Apivar ${ }^{\circledR}$ and four colonies treated with Apilife $\operatorname{Var}^{\circledR}$ as positive control. We also analysed some mites collected in 2020 as part of the U.S. National Honey Bee Disease Survey (NHBDS). We looked at samples collected from Delaware, Massachusetts, Montana and Pennsylvania. Mite samples previously used to detect tau-fluvalinate resistance in U.S. mite populations and collected from these same states but from 2016 and 2017 NHBDS efforts, were also used (Millán-Leiva et al. 2021a). Samples from New Jersey were sent by a New Jersey state apiarist and were collected from apiaries reporting amitraz failure in 2018 (Styles, Personal communication).

Susceptible samples were collected from 2016 to 2019 in apiaries without exposure to amitraz from Iran, New Zealand, Spain, and the UK.

\section{Identification of receptors and phylogenetic analysis}

Analysis of the contigs resulting from a transcriptomic analysis of $V$. destructor were previously carried out by our laboratory (BioProject ID PRJNA531374), allowing us to annotate putative octopamine-like receptors. The identity of these sequences was validated after searching in the $V$. destructor genome (BioProject PRJNA413423) (Techer et al. 2019) via BLASTn. Further comparison with previously annotated octopamine and tyramine receptors from related arthropod species was also carried out via multiple sequence alignment (47 sequences of octopamine and tyramine receptors were used, see Table S2). Protein alignments, tree generation for the phylogenetic analysis, electropherogram editions and sequence assembling were conducted using Geneious software (Geneious version 9.1.5 (http://www.geneious.com (Kearse et al. 2012)). Figures representing protein alignments were generated using CLC Sequencer Viewer 6.8.1. (www.clcbio.com).

\section{Amplification and sequencing of receptor CDNAs}

Pools of 5 mites were ground to powder in liquid nitrogen, and total RNA was extracted using the RNeasy Mini Kit (Qiagen) according to the manufacturer's recommendations. RNA $(0.5-1 \mu \mathrm{g})$ was reverse transcribed to cDNA using Maxima $\mathrm{H}$ minus First Strand cDNA synthesis kit (ThermoFisher Scientific) using oligo $\mathrm{dT}_{18}(250 \mathrm{ng}$ ). First strand cDNA was used as a template for PCR. Amplification of $V d_{-}$oct $\alpha_{2} r$ Open Reading Frame (ORF) was conducted using primers Vd_OctAR_5UTR and Vd_OctAR_3UTR. 
Amplification of $V d \_o c t \beta_{2} r$ ORF was done using primers Vd_OctBR_5UTR1 and Vd_OctBR_3UTR. Amplification of Vd_tarl ORF was carried out using primers $\mathrm{Vd}$ TAR1_5F and TAR1_3R (Table S3). For PCR amplifying the ORFs, $1 \mu \mathrm{l}$ of cDNA was mixed with $100 \mathrm{ng}$ of each primer, $25 \mu$ of DreamTaq Green PCR Master Mix (ThermoFisher Scientific) and water to a final volume of $50 \mu$ l. Cycling conditions were: $94{ }^{\circ} \mathrm{C}$ for 2 min followed by 35 cycles of $94{ }^{\circ} \mathrm{C}$ for $45 \mathrm{~s}, 60^{\circ} \mathrm{C}$ for $45 \mathrm{~s}$ and $72{ }^{\circ} \mathrm{C}$ for $2 \mathrm{~min}$, and final extension at $72{ }^{\circ} \mathrm{C}$ for $5 \mathrm{~min}$. The PCR fragments were purified using the NucleoSpin ${ }^{\mathrm{TM}} \mathrm{Gel}$ and PCR Cleanup Kit (Thermo Scientific) and sequenced (Stabvida, Portugal) using the sets of primers showed in Table S3.

\section{Genomic DNA sequencing}

DNA was extracted from individual mites using DNAzol ${ }^{\circledR}$ reagent (ThermoFisher Scientific) following the manufacturer's protocol. Primers used to PCR amplify and sequence the octopamine and tyramine receptor genes are described in Table S3. The mutation at position 260 of $V d \_o c t \beta_{2} r$ was screened by amplifying the genomic region flanking the mutation site with primers Vd_OctBR_5UTR3 and Vd_OctBR_563R. The flanking region of the mutation at position 643 of $V d_{-}$oct $\beta_{2} r$ was amplified with primers $\mathrm{Vd}$ OctBR_476F and Vd_OctBR_437iR. The PCR conditions were similar to those described above except for the extension step, which was run at $72{ }^{\circ} \mathrm{C}$ for $1 \mathrm{~min}$. PCR amplicons were purified and sequenced as described above.

\section{Protein structure simulation}

The online server for protein structure prediction I-TASSER (Yang and Zhang 2015) was used to generate a theoretical three-dimensional structure of $V$. destructor $\operatorname{Oct}_{2} \mathrm{R}$ and TAR1. From the default settings of I-TASSER, the structure conformation with higher $\mathrm{C}$-score for each receptor was chosen. C-score is typically in the range of $[-5,2]$, where a $\mathrm{C}$-score of a higher value indicates a model with a higher confidence and vice-versa. The topology of the Oct $\beta_{2} \mathrm{R}$ receptor in the membrane was represented using the webservice PROTTER (Omasits et al. 2014), which uses Phobius (Kall et al. 2004) for prediction of transmembrane topology and the $\mathrm{N}$-terminal location. The predictions about the effects of the mutations in the receptor were obtained with SNAP2 (Hecht et al. 2015), PolyPhen2 (Adzhubei et al. 2010), I-Mutant2.0 (https://folding.biofold.org/i-mutant/imutant2.0.html), and HOPE (Venselaar et al. 2010).

\section{TaqMan diagnostic assays}

The sequence of the $V d \_o c t \beta_{2} r$ gene described in this study was used to design primers (flanking the N87 and
Y215 positions in the Vd_Oct $\beta_{2} \mathrm{R}$ protein) and two minor groove-binding probes (MGB) (ThermoFisher Scientific) using the Custom TaqMan ${ }^{\circledR}$ Assay Design Tool (https:// www.thermofisher.com/order/custom-genomic-products/ tools/genotyping/). For the detection of N87S mutation, forward OctR_Vd_87_F (5'-CGCCCTGTTCGCGATGA$\left.3^{\prime}\right)$ and reverse OctR_Vd_87_R (5'-ATCCACTTGCCC GAAATGGT-3') primers (standard oligonucleotides with no modification) were used. The probe Vd_N87S_V (5'ACGACGCATTGAATG-3') was labelled with the fluorescent dye $\mathrm{VIC}^{\circledR}$ for the detection of the wild-type allele, and the probe Vd_N87S_M (5'-CGACGCACTGAATG-3') was labelled with the fluorescent dye $6 \mathrm{FAM}^{\mathrm{TM}}$ for detection of the N87S mutation. For the detection of Y215H mutation, forward OctR_Vd_215_F (5'-GGATACCGTGCTCAGTAA TGCT-3') and reverse OctR_Vd_215_R (5'-CTGTCGGGT CGCTTCTAGATAG- $3^{\prime}$ ) primers (standard oligonucleotides with no modification) were used. The probe Vd_Y215H_V (5'-ATGCGCCAATAAGTGAAT-3') was labelled with the fluorescent dye $\mathrm{VIC}^{\circledR}$ for the detection of the wild-type allele, and the probe Vd_Y215H_M (5'-CGCCAATGAGTG AAT-3') was labelled with the fluorescent dye $6 \mathrm{FAM}^{\mathrm{TM}}$ for detection of the $\mathrm{Y} 215 \mathrm{H}$ mutation. Each probe also had a 3 'non-fluorescent quencher and a minor groove binder at the 3 ' end. This minor groove binder increases the Tm between matched and mismatched probes providing more accurate allele discrimination (Afonina et al. 1997). Genomic DNA extraction from adult mites and TaqMan assays were carried out as described by González-Cabrera et al. (2013) using a StepOne Real-Time PCR System (ThermoFisher Scientific).

\section{Results}

\section{Identification of $V$. destructor octopamine and tyramine receptors}

Manual curation of transcriptomic data obtained in our laboratory (BioProject ID PRJNA531374) showed that a few contigs contained sequences likely belonging to $\mathrm{G}$ protein-coupled receptors (GPCR) and more specifically to octopamine-like receptors. These were used as queries to search via BLASTn in the recently released $V$. destructor genome (Techer et al. 2019). Thus, contigs c139848_g8_i1 (1227 bp), and c143491_g6_i5 (2547 bp), mapped to the locus LOC111253729, annotated as a G-protein couple receptor (XP_022669321.1), and to the locus LOC111251882, annotated as an octopamine receptor beta-2R-like (XP_022664702.1), respectively. Since in Rhipicephalus microplus, a tyramine receptor (GenBank accession number CAA09335) was previously associated with resistance to amitraz (Kumar 2019), the homologous 
gene was searched in the $V$. destructor's genome. The locus LOC111254088, annotated as octopamine-like receptor in the $V$. destructor database, showed the highest identity with the gene encoding the CAA09335 protein from $R$. microplus. Phylogenetic analysis was then conducted with these proteins and with others, annotated as octopamine receptors, from several arthropod species (Table S2). The phylogenetic tree obtained from the alignment of 47 proteins clustered into three main groups, consisting of $\alpha_{2}$-adrenergic-like octopamine receptors (Oct $\alpha_{2}$ Rs), $\beta$-adrenergic-like octopamine receptors (Oct $\beta$ Rs), and type 1 Tyramine receptors
(TAR1). The branch corresponding to Oct $\beta$ Rs included three classes of receptors: Oct $\beta_{1} R$, Oct $\beta_{2} R$, and Oct $\beta_{3} R$. Regarding the proteins from $V$. destructor in the alignment, XP_022669321 grouped with Oct $\alpha_{2}$ Rs; XP_022664702 is included in the branch corresponding the Oct $\beta_{2} \mathrm{Rs}$, and XP_022670329 is related with TAR1s (Fig. 1). From this analysis, we called XP_022669321, XP_022664702, and XP_022670329 proteins, as Vd_Oct $\alpha_{2} R$, Vd_Oct $\beta_{2} R$, and Vd_TAR1, respectively.

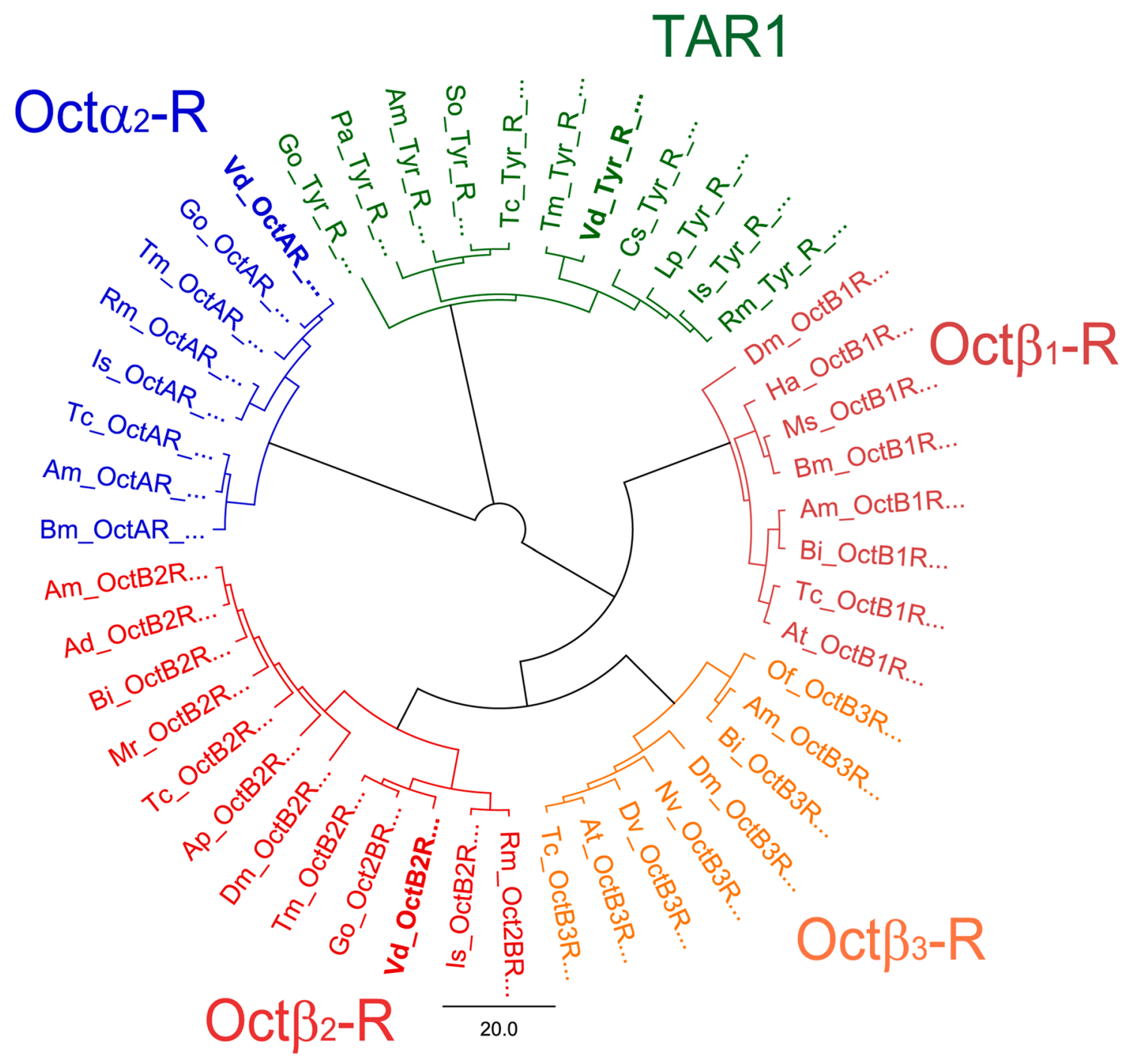

Fig. 1 Phylogenetic tree of octopamine receptors across several species of arthropods. Neighbour-Joining tree was constructed in Geneious 9.1.8. Oct $\alpha_{2} R$ : $\alpha_{2}$-adrenergic-like octopamine receptor; Oct $\beta_{1} R$ : octopamine $\beta_{1}$ receptor; Oct $\beta_{2} R$ : octopamine $\beta_{2}$ receptor; Oct $\beta_{3} \mathrm{R}$ : octopamine $\beta_{3}$ receptor; TAR1: type 1 tyramine receptor. Ac: Acyrthosiphon pisum; Ae: Aethina tumida; Am: Apis dorsata; Am; Apis mellifera; Bi: Bombus impatiens; Bm: Bombyx mori; Cs: Centruroides sculpturatus; Dv: Diabrotica virgifera virgifera; Dm:
Drosophila melanogaster; Go: Galendromus occidentalis; Ha: Helicoverpa armigera; Is: Ixodes scapularis; Lp: Limulus polyphemus; Ms: Manduca sexta; Mr: Megachile rotundata; Nv: Nicrophorus vespilloides; Of: Ostrinia furnacalis; Pa: Periplaneta americana; $\mathrm{Rm}$ : Rhipicephalus microplus; Tc: Tribollium castaneum; Tm: Tropilaelaps mercedesae; Vd: Varroa destructor. The GenBank accession numbers of the receptor sequences in the tree are listed in Table S2 

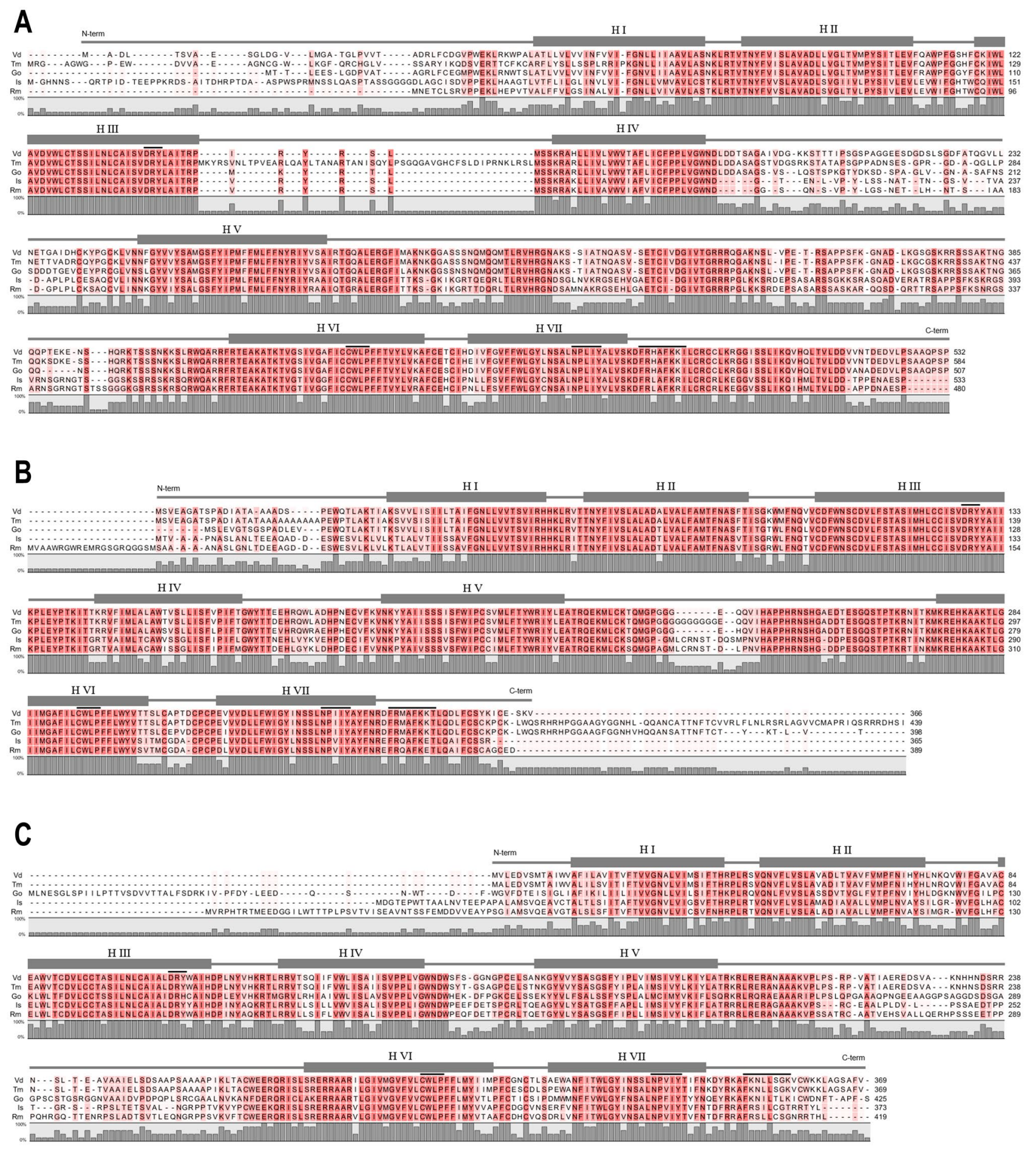

Fig. 2 Multiple sequence alignment of $\operatorname{Oct} \alpha \operatorname{Rs}(\mathbf{A}), \operatorname{Oct} \beta \operatorname{Rs}(\mathbf{B})$, and TAR1 (C) from diverse acari species. The shaded sequences highlight the amino acid identity level. The seven $\alpha$-helices are represented as grey rectangles and numbered as H I-VII. GPCR conserved motifs in helix III (D[E]RY), helix VI (CWxP), helix VII (NP[L/I]IY), and C-terminus $(\mathrm{F}[\mathrm{R} / \mathrm{K}] \mathrm{xx}[\mathrm{F} / \mathrm{L}] \mathrm{xxx})$ are indicated by bars. Vd: Varroa destructor; Tm: Tropilaelaps mercedesae; Go: Galendromus occidentalis; Is: Ixodes scapularis; Rm: Rhipicephalus microplus 


\section{Vd_Oct $\boldsymbol{a}_{2} R$ protein}

Vd_Oct $\alpha_{2} \mathrm{R}$ encoded for a 532 amino acids protein. When Vd_Oct $\alpha_{2} R$ was aligned to other $\alpha$-adrenergic-like octopamine receptors, a high degree of conservation was observed among species, mainly in the regions corresponding to the predicted seven $\alpha$-helices of the proteins' tertiary structure (Fig. 2A). The percentage of identity between Vd_Oct $\alpha_{2} \mathrm{R}$ and the $\alpha$-receptors from other Acari species was $82 \%$ for Galendromus occidentalis, $68 \%$ for Tropilaelaps mercedesae, $52 \%$ for R. microplus and 50\% for Ixodes scapularis. Conserved motifs common to GPCR were found in $\alpha$-helices III, VI, VII, and the C-terminus (Fig. 2A).

\section{Vd_Oct $\boldsymbol{\beta}_{2} R$ protein}

Vd_Oct $\beta_{2} R$ encoded for a 439 amino acids protein. The percentage of identity between Vd_Oct $\beta_{2} R$ and the $\beta$-adrenergic-like octopamine receptor from other closely related Acari species in the cladogram were $83 \%$ for $T$. mercedesae, $79 \%$ for G. occidentalis, $68 \%$ for R. microplus and $65 \%$ for I. scapularis. Multiple sequence alignment of Oct $\beta$ Rs from these species showed that, as in Vd_Oct $\alpha_{2} R$, Vd_Oct $\beta_{2} \mathrm{R}$ contained highly conserved regions corresponding to the seven $\alpha$-helices typical of GPCR (Fig. 2B). The modelling of the Vd_Oct $\beta_{2} \mathrm{R}$ three-dimensional structure, obtained with I-TASSER online server, showed the common structure described in GPCRs: seven transmembrane
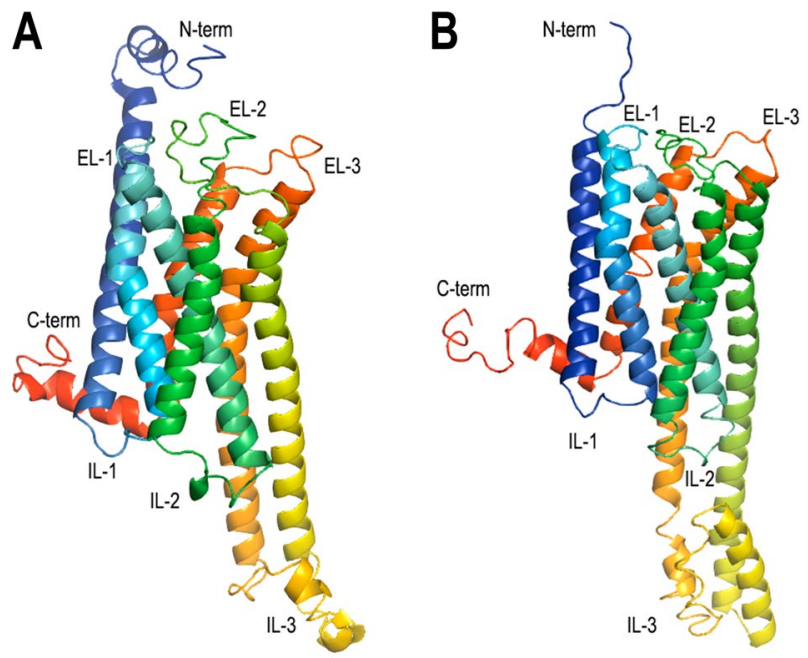

Fig. 3 Three-dimensional structure of Vd_Oct $\beta_{2} R(\mathbf{A})$ and Vd_TAR1 (B), obtained by modelling with I-TASSER (Yang and Zhang 2015). The receptors are showed as ribbon representation in rainbow colouring ( $\mathrm{N}$-terminus, blue; $\mathrm{C}$-terminus, red). The seven $\alpha$-helices are connected by three extracellular loops (EL1-3) and three intracellular loops (IL1-3)

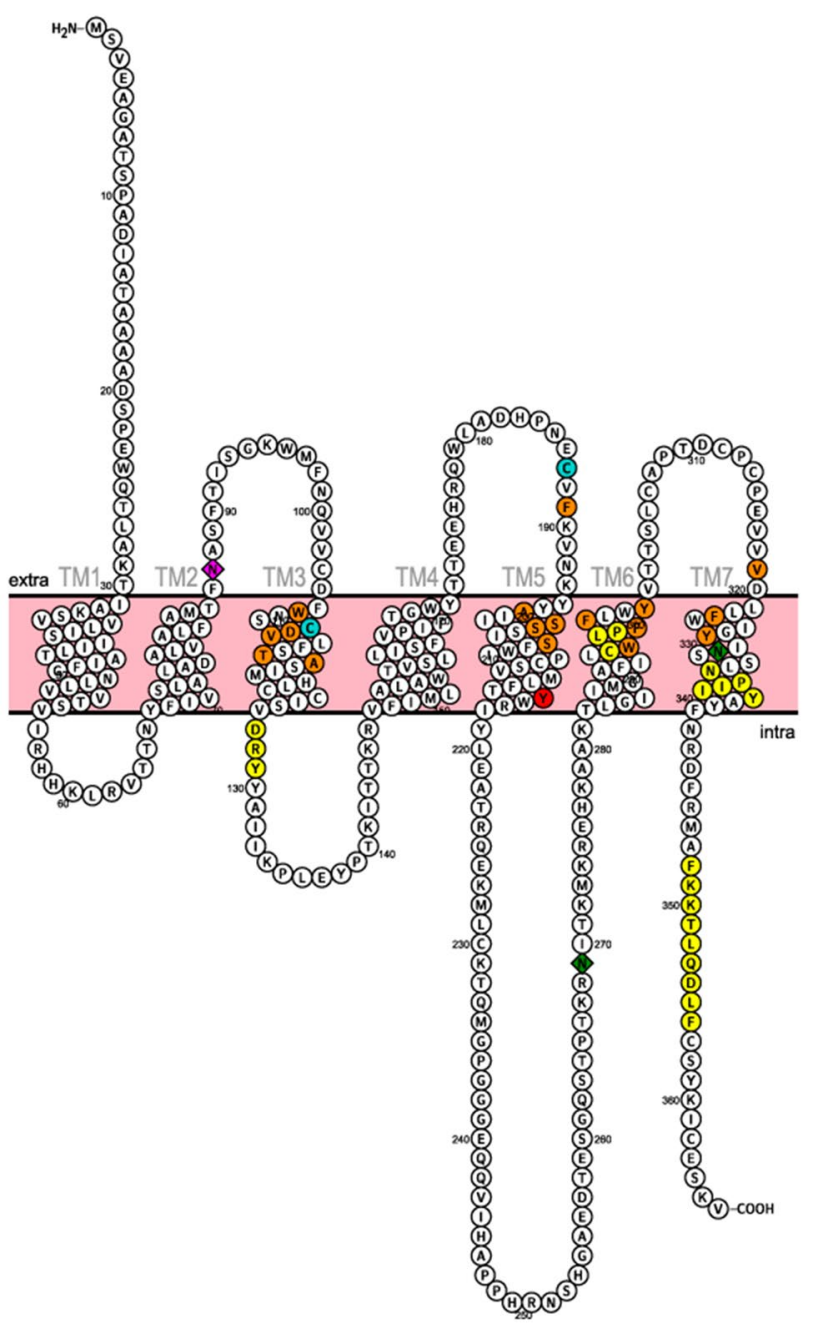

Fig. 4 Snake plot of Vd_Oct $\beta_{2} \mathrm{R}$ with transmembrane domains predicted with Phobius (Kall et al. 2004). N87S mutation (magenta); Y215 mutation (red); putative $\mathrm{N}$-glycosylation residues (diamond); GPCR conserved motifs (yellow); putative disulphide bond residues (blue); predicted ligand binding residues (orange)

(TM) helical bundle connected by three extracellular loops (EL) and three intracellular loops (IL) (Fig. 3A). The N-terminus of the protein was at the extracellular side and the C-terminus was located intracellularly. In this structure, the ligand-pocket would be close to the extracellular region and surrounded by the transmembrane helical domain (Marsh 2015). The molecular simulation of transmembrane regions using Phobius software predicted which residues were "buried" into the membrane or exposed to intracellular or extracellular regions (Fig. 4). Other features characterizing Oct $\beta \mathrm{R}$ were also found in $\mathrm{Vd}$ _Oct $\beta_{2} \mathrm{R}$ (Fig. 4). The receptor had two highly conserved cysteine residues in TM3 and EL2 which form a disulphide bond, which is important for 
stabilizing the conformation of the extracellular region and shaping the entrance to the ligand-binding pocket (Rader et al. 2004). Three motifs of amino acids involved in molecular switches in GPCRs during activation were also found in Vd_Oct $\beta_{2} R$ : (i) the D[E]RY motif in helix III, which often forms a so-called ionic lock. The ionic lock was suggested as a characteristic of the inactive conformation of GPCRs, blocking the G-protein binding at the cytoplasmic region; (ii) the CWxP motif observed in $\alpha$-helix VI, considered as one of the micro-switches that have substantially different conformations in the active state versus the inactive state of the receptor; iii) the NP(L/I)IY motif in helix VII, involved in a permanent rotameric change (Filipek 2019) (Fig. 2B and Fig. 4). As in most of the GPCR structures, the C-terminus contains a $3-4$ turn $\alpha$-helix, $\alpha$-helix VIII, that runs parallel to the membrane and is characterized by a common $(\mathrm{F}[\mathrm{R} / \mathrm{K}]$ $\mathrm{xx}[\mathrm{F} / \mathrm{L}] \mathrm{xxx}$ ) amphiphilic motif (Zhang et al. 2015). Putative amino acids involved in octopamine binding are extended through a 222 amino acids region between W106 and Y327.

\section{Vd_TAR1 protein}

Vd_TAR1 encoded for a 369 amino acids protein. Vd_TAR1 was aligned to the Acari tyramine receptors more similar to the tyramine receptor of $R$. microplus (CAA09335), in which mutations associated with resistance to amitraz have been described (Kumar 2019). As with Vd_Oct $\alpha_{2} \mathrm{R}$ and Vd_ $\operatorname{Oct} \beta_{2} R$, the regions corresponding to the predicted seven helices in the tertiary structure of the proteins are conserved among species (Fig. 2C). The modelling of the three-dimensional structure Vd_TAR1 also showed the described structure for GPCR: seven hydrophobic transmembrane domains and six hydrophilic loops (Fig. 3B). Like in other TAR1 receptors, the third intracellular loop of Vd_TAR1 is longer than that in Oct $\beta_{2}$ Rs. The percentage of identity between Vd_TAR1 and the tyramine receptors from other Acari species is $94 \%$ for T. mercedesae, $61 \%$ for R. microplus and for I. scapularis, and $56 \%$ for $G$. occidentalis.

\section{$V d \_o c t a_{2} r, V d \_o c t \beta_{2} r$ and Vd_tar1 genes}

The cDNA of $V d \_o c t \alpha_{2} r, V d \_o c t \beta_{2} r$ and $V d \_t a r l$ was obtained by RT-PCR, using as template the same RNA samples used for transcriptomics. Sequencing of the ORFs showed a full identity of these cDNAs with XM_022813586, XM_022808967 and XM_022814594, corresponding to the mRNA of Vd_Oct $\alpha_{2} R$, Vd_Oct $\beta_{2} R$, and Vd_TAR1.

The ORF of $V d \_$oct $\alpha_{2} r$ has a length of $1599 \mathrm{bp}$, and the full gene is $155,562 \mathrm{bp}$ long. The Vd_oct $\alpha_{2} r$ gene comprises nine exons and eight introns (Fig. 5A). The 5'UTR is extended along Exon 1, Exon 2 and Exon 3. The start codon (position 3,746 at the mRNA) is sited in Exon 4. The stop
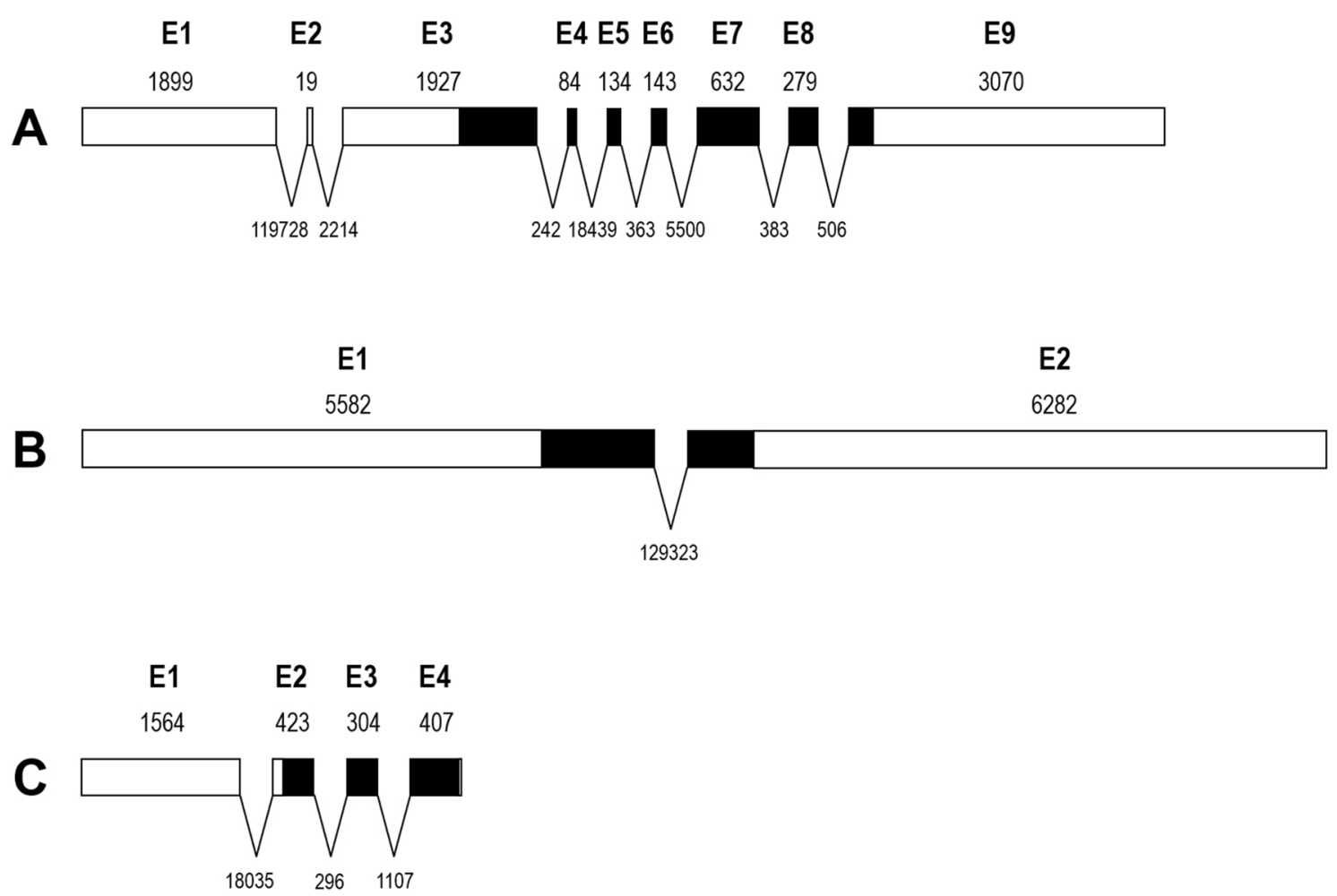

Fig. 5 Schematic diagram of $\operatorname{oct}_{2} r(\mathbf{A})$, oct $\beta_{2} r(\mathbf{B})$, and $\operatorname{tarl}(\mathbf{C})$ exon-intron gene structure. Coding sequence (CDS) is shown in black. Lengths are represented in bp 
codon (position 5,344 at the mRNA) and the 3'UTR are in the Exon 9, the largest exon. The length of all the exons and introns of $V d \_$oct $\alpha_{2} r$ is shown in Fig. 5A.

The lengths of $V d \_o c t \beta_{2} r$ ORF, mRNA, and full gene sequences are $1101 \mathrm{bp}, 11,863 \mathrm{bp}$, and 141,186 bp, respectively. The $V d \_$oct $\beta_{2} r$ gene comprises two exons and one intron (Fig. 5B). Exon 1 contains the 5'UTR and the start codon (position 4507 at the mRNA), and Exon 2 contains the stop codon (position 5607 at the mRNA) and the 3'UTR. Between Exon 1 and Exon 2 there is a long intron of 129,323 bp (Fig. 5B).

The Vd_tarl gene has a length of $22,226 \mathrm{bp}$, transcribed into an mRNA of $2788 \mathrm{bp}$ in which an ORF of $1110 \mathrm{bp}$ is found. The Vd_tarl gene comprises 4 exons and 3 introns (Fig. 5C). The 5'UTR is extended along Exon 1 and Exon 2. The start codon (position 1162 at the mRNA) is sited in

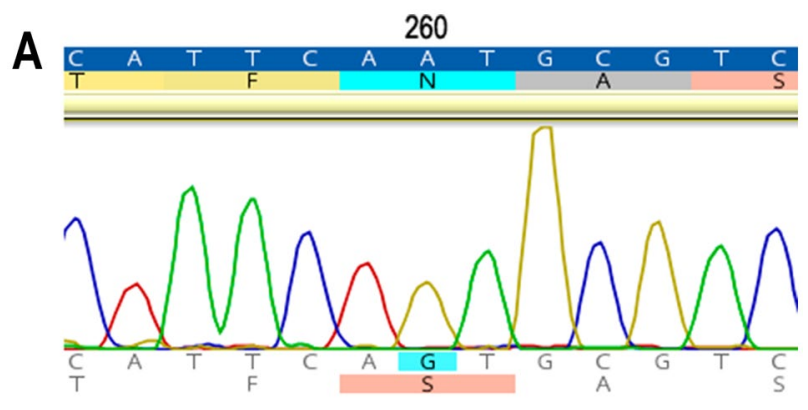

B

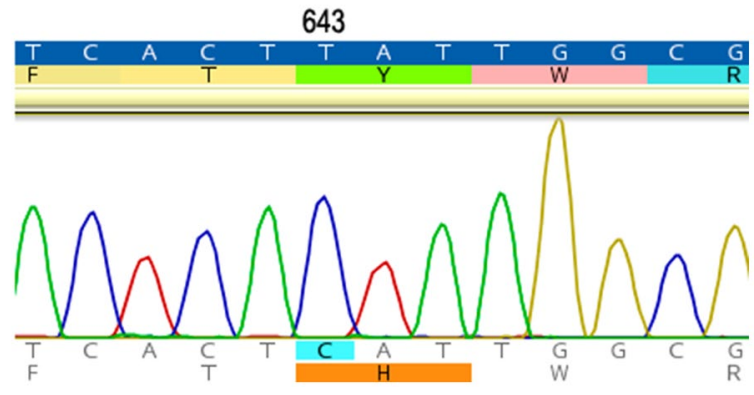

Fig. 6 Electropherograms showing the mutations in the sequence of $V d \_o c t \beta_{2} r$. The substitution of A by $\mathrm{G}$ at position 260 of the ORF results in the N87S mutation (A), whereas the substitution of $\mathrm{T}$ by $\mathrm{C}$ at position 643 results in the $\mathrm{Y} 215 \mathrm{H}$ mutation $(\mathbf{B})$
Exon 2. The stop codon (position 2769 at the mRNA) and the 3'UTR are in the Exon 4. The length of all the exons and introns of Vd_tarl is shown in Fig. 5C.

\section{$V d \_o c t \beta_{2} r$ and $V d \_t a r 1$ sequences in $V$. destructor mites susceptible to amitraz}

Total RNA was isolated from pools of five to ten V. destructor adult females collected in Iran, New Zealand, Spain and the UK between 2016 and 2019 from colonies without amitraz treatment. As mutations associated with the resistance to amitraz has been described in Oct $\beta R$ and TAR1 receptors, RNA from these susceptible mites was reverse transcribed into cDNA to amplify the full length of $V d \_o c t \beta_{2} r$ and $V d \_t a r l$ ORFs. The sequencing of $V d \_o c t \beta_{2} r$ and $V d_{-}$ tarl ORFs of mites from these countries showed identical sequences to those previously identified as wild-type in this paper (XM_022813586 and XM_022814594, respectively).

\section{$V d \_o c t \beta_{2} r$ N87S mutation}

We identified a single point mutation in $V d \_o c t ~ \beta_{2} r$ gene (substitution of A to $\mathrm{G}$ at nucleotide 260 of the ORF) in mites extracted alive from the brood, right after finishing the treatment with amitraz, in colonies of apiary DTRA (Isère department, France), that reported failure of this treatment. This mutation results in an asparagine (AAT) to serine (AGT) substitution at position 87 of the $\mathrm{Vd} \_O c t{ }_{2} \mathrm{R}$ protein (N87S) (Fig. 6A). To validate this result, total DNA was isolated from 24 individual mites collected in 3 colonies from the same apiary. The genomic region comprising the mutation was amplified and sequenced. All sequenced mites showed the N87S mutation (Table 1). The same analysis was carried out with mites from the apiaries MAP (Loire department) and MHRA (Isère department), where the treatment with amitraz also failed. The mutation was present in $75 \%$ of the mites from MAP apiary, and in $71 \%$ of the mites from the MHRA apiary (Table 1). In colonies MM16 and J11 (both located in apiaries at Puy-de-Dôme department) the mutation N87S was detected in 77 and $57 \%$ of the mites, respectively (Table 1). Further analysis showed that the efficacy of amitraz treatment was $92 \%$ in colony MM16
Table 1 Frequency of the N87S mutation in the samples collected from several French departments

\begin{tabular}{lllllc}
\hline Colony & Department & $n$ & Last treatment & Collection & \% N87S mutation \\
\hline DTRA & Isère (38) & 24 & Amitraz & POST-Treatment & 100 \\
MAP & Loire (42) & 24 & Amitraz & POST-Treatment & 75 \\
MHRA & Isère (38) & 24 & Amitraz & POST-Treatment & 71 \\
J11 & Puy-de-Dôme (63) & 23 & Amitraz & POST-Treatment & 74 \\
MM16 & Puy-de-Dôme (63) & 24 & Amitraz & POST-Treatment & 58 \\
VBA & Alpes-de-Haute-Provence (04) & 20 & Oxalic acid & PRE-Treatment & 0 \\
AmA & Maine-et-Loire (49) & 24 & Oxalic acid & PRE-Treatment & 0 \\
DE & Drôme (26) & 19 & Oxalic acid & PRE-Treatment & 26 \\
\hline
\end{tabular}


and $77 \%$ in $\mathrm{J} 11$. The occurrence of this mutation was also studied in three apiaries from nearby departments in which amitraz was not used the year before sampling. Apiaries VB (Alpes-de-Haute-Provence department), AmA (Maineet-Loire department) and DE (Drôme) were all treated with oxalic acid. None of the mites from VB and AmA carried the mutation N87S, while $26 \%$ of the mites from DE were mutants (Table 1). Altogether, these data show circumstantial evidence that there is an association between the mutation $\mathrm{N} 87 \mathrm{~S}$ and amitraz treatment failure.

The ORF of Vd_tarl was also sequenced in pools of mites collected from all French apiaries analysed in this study. None of the analysed mites showed any change in the sequence when compared with the wild-type Vd_tarl.

\section{Y215H mutation}

In the USA, a state apiary inspector reported the failure of the amitraz treatment in some colonies from New Jersey in 2018 (Styles, Personal communication). The Vd_oct $\beta_{2} r$ and $V d \_t a r l$ gene sequences were examined in mites collected from four of these colonies. No mutations were detected in $V d \_t a r 1$ gene and the mutation N87S, identified in French samples, was also not detected. However, a new single point mutation was identified in the $V d \_o c t ~ \beta_{2} r$ gene from mites collected from the four colonies. The substitution of $\mathrm{T}$ to $\mathrm{C}$ at position 643 of the ORF results in a tyrosine (TAT) to histidine (CAT) substitution at position 215 of the $\mathrm{Vd}$ _Oct $\beta_{2} \mathrm{R}$ protein (Y215H) (Fig. 6B). This mutation was detected in 50 to $96 \%$ of the mites sequenced from these colonies (Fig. 7, Table S1).

In order to gather data regarding the presence of the mutation $\mathrm{Y} 215 \mathrm{H}$ in New Jersey from previous years, mites collected in 2016 from different colonies in this state were also sequenced. We did not detect this mutation in any of the colonies analysed (Fig. 7, Table S1).

Since the presence of the $\mathrm{Y} 215 \mathrm{H}$ mutation seemed related with the reduced susceptibility to amitraz, we analysed mite samples obtained from a BIP project evaluating the efficacy to Apivar ${ }^{\circledR}$ in Oregon and Michigan in 2018. These trials were suggestive of amitraz treatment failure (Nathalie Steinhauer, personal communication). Samples of phoretic $V$. destructor mites were collected from bees sampled from colonies, while being treated with Apivar ${ }^{\circledR}$. The Y215H mutation was detected in 88 and $96 \%$ of the mites from the two colonies we examined that were treated with Apivar $^{\circledR}$ in Oregon, and in the 94 and $90 \%$ of the mites from the two colonies treated with Apivar ${ }^{\circledR}$ in Michigan (Fig. 7, Table S1). Colonies from the same apiaries but treated with thymol instead of Apivar ${ }^{\circledR}$ were also analysed. The Y215H mutation was present in 96 and $100 \%$ of the mites collected in the two colonies from Oregon and the same frequencies were also

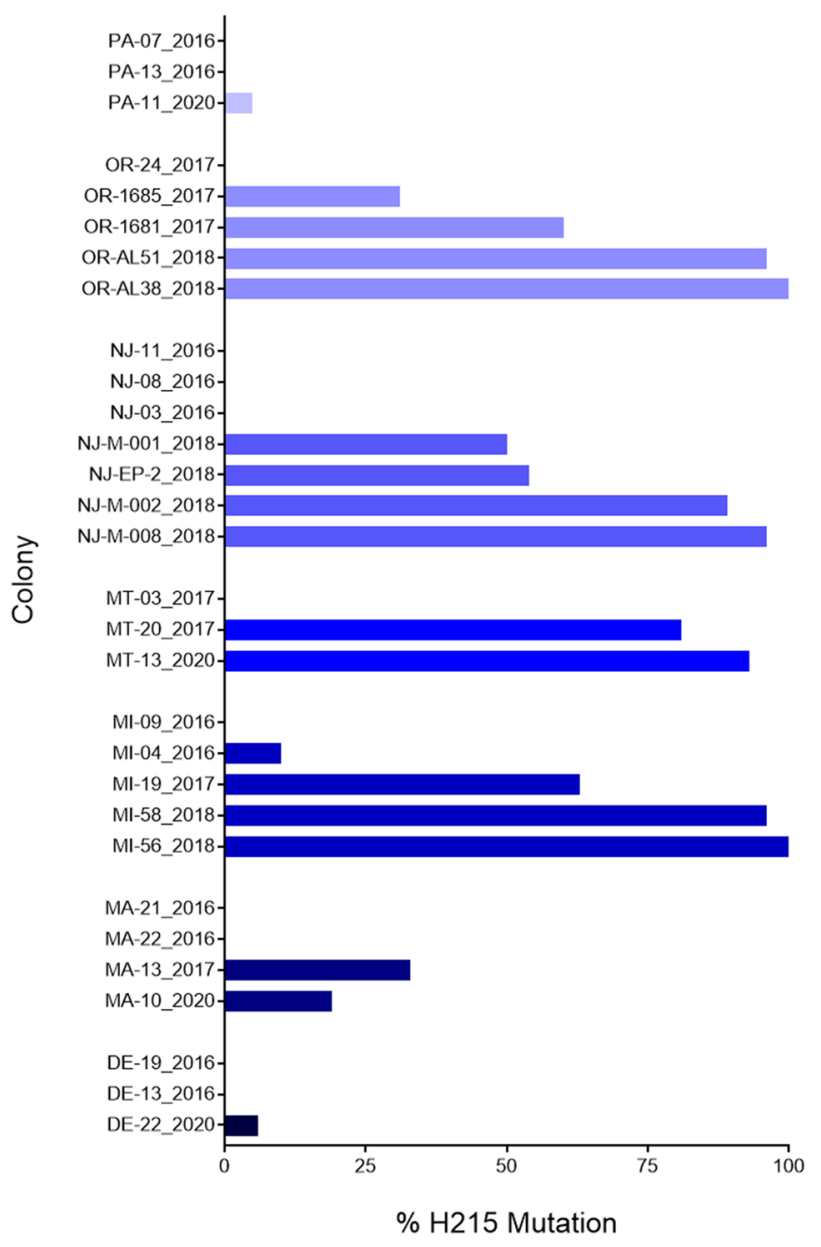

Fig. 7 Timeline of the $\mathrm{Y} 215 \mathrm{H}$ mutation incidence in colonies from USA. The name of the colonies in the Y axe shows the state and the year of sample collection. DE: Delaware; MA: Massachusetts; MI: Michigan; MT: Montana; NJ: New Jersey; OR: Oregon; PA: Pennsylvania. More detailed information can be found in Table S1

recorded in the two colonies from Michigan (Table S1). On the other hand, mites collected from these two states before 2018 (Millán-Leiva et al. 2021a) were also sequenced. The mutation was found but at much lower frequency, suggesting that the mutation is a relatively recent event (Fig. 7, Table S1).

To estimate when the mutation first evolved in the U.S. population, we compared the presence of $\mathrm{Y} 215 \mathrm{H}$ in samples collected in 2020 with samples collected in previous years in several U.S. states (Millán-Leiva et al. 2021a). Results from Delaware, Massachusetts, Montana and Pennsylvania showed that the mutation was practically non-existent in 2016 but its incidence has increased since (Fig. 7, Table S1).

French samples were also screened to detect $\mathrm{Y} 215 \mathrm{H}$ mutation. None of the samples tested showed this mutation. 


\section{Diagnostic assay}

Two high throughput allelic discrimination assays based on TaqMan technology were developed to enable rapid and accurate genotyping of $\mathrm{N} 87 \mathrm{~S}$ and $\mathrm{Y} 215 \mathrm{H}$ mutations in individual mites. For each real-time PCR assay, we designed two fluorescent labelled probes to discriminate between wildtype and mutant alleles. The probes selective for N87 or Y215 wild-type alleles were labelled with VIC ${ }^{\circledR}$ while the others, selective for $\mathrm{S} 87$ or $\mathrm{H} 215$ alleles, were labelled with $6 \mathrm{FAM}^{\mathrm{TM}}$. Therefore, an increase in $\mathrm{VIC}^{\circledR}$ fluorescence indicates the presence of the wild-type allele, while an increase in $6 \mathrm{FAM}^{\mathrm{TM}}$ fluorescence indicates the presence of the mutant allele. An intermediate increase in the fluorescence of both dyes indicates that the mite is heterozygous for the mutation. Twenty-four mites, in which the nucleotide at each
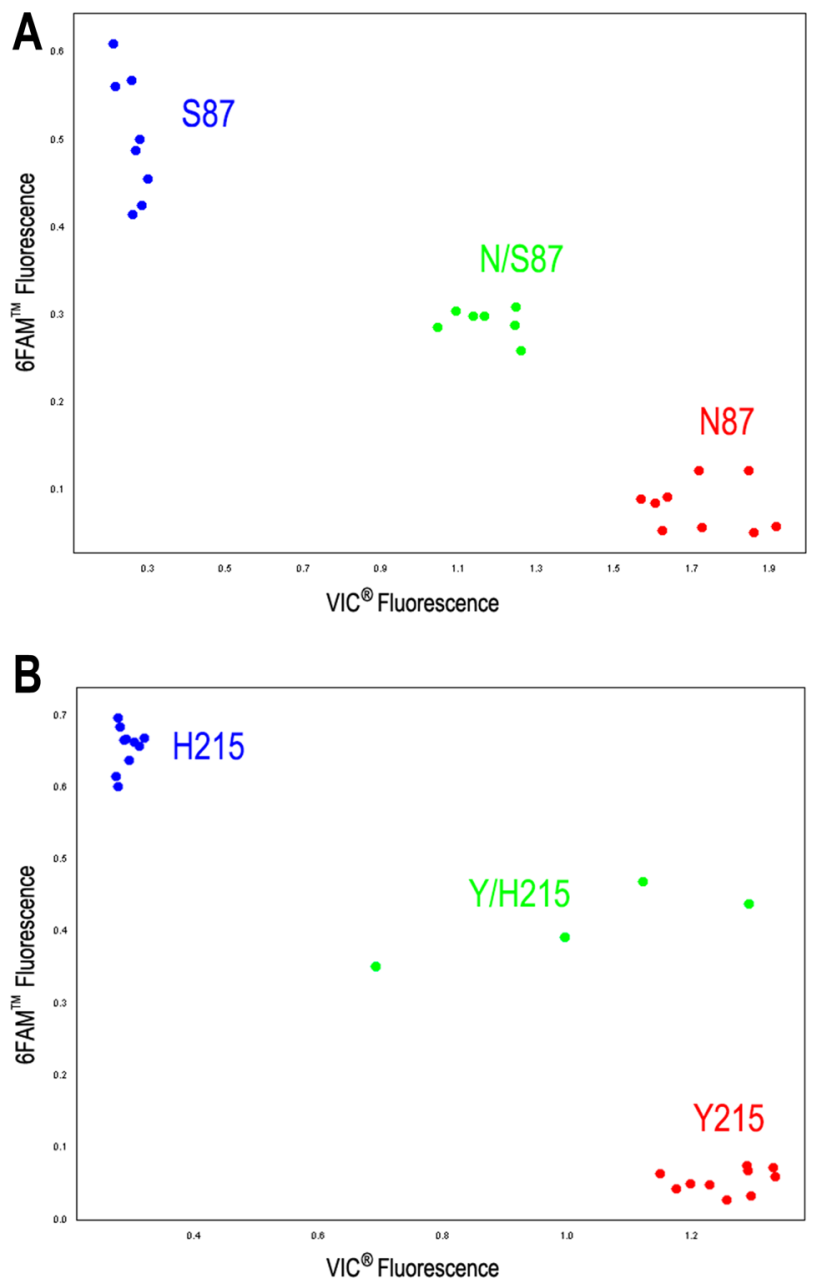

Fig. 8 Real-time TaqMan ${ }^{\circledR}$ detection of the N87S (A) and Y215H (B) mutations in Vd_Oct $\beta_{2} R$. In the scatter plots of VIC ${ }^{\circledR}$ and 6FAM ${ }^{\mathrm{TM}}$ fluorescence, each dot represents an individual mite. SS homozygotes (N87 or Y215 allele) in red; RS heterozygotes in green; RR homozygotes (S87 or $\mathrm{H} 215$ allele) in blue of the mutation sites of $V d \_o c t ~ \beta_{2} r$ was known by previous sequencing, were genotyped by TaqMan assay. The results showed a complete agreement between data from sequencing and genotyping. Genotyped mites were either homozygous for the wild-type allele (N87 or Y215), the mutant allele (S87 or H215), or heterozygous for each mutation (Fig. 8).

\section{Discussion and conclusion}

Here we identified two amino acid substitutions, located in the $\beta$-adrenergic octopamine receptor of $V$. destructor, that seem to be associated with field treatment failures using amitraz in samples collected in France and the USA. Our data also show circumstantial evidence of an independent evolution of resistance in both locations.

Amitraz is a formamidine that has been widely used as an acaricide since its discovery back in 1972 (Harrison et al. 1972). Nowadays, it is one of the main alternatives for controlling varroosis worldwide. This compound mimics the action of the neurotransmitters octopamine and tyramine and blocks their receptors (Hollingworth and Lund 1982). Therefore, it is likely that modifications in key sites of the octopamine or tyramine receptors would be associated with the treatment failures reported by beekeepers after treatments with amitraz-based acaricides.

A joint analysis of transcriptomic (BioProject ID PRJNA531374) and genomic data (Techer et al. 2019), alongside with data available in public databases, allowed the characterization of proteins from three different classes of receptors in this mite: an $\alpha$-adrenergic-like octopamine receptor $\left(\mathrm{Vd} \_O c t \alpha_{2} \mathrm{R}\right)$, a $\beta$-adrenergic-like octopamine receptor $\left(\mathrm{Vd} \_\mathrm{Oct} \beta_{2} \mathrm{R}\right)$ and a tyramine type 1 receptor $\left(\mathrm{Vd}_{-}\right.$ TAR1). A more in-depth in silico study of the secondary and tertiary structures of these proteins showed that they have structural features typical of the superfamily of G-protein coupled receptors, such as the seven transmembrane domains and the classic distribution of extracellular and intracellular loops (Finetti et al. 2021). Moreover, the occurrence of highly conserved residues and several sequence motifs common to $\alpha$ - and $\beta$-adrenergic octopamine receptors in Vd_Oct $\alpha \mathrm{R}$ and $\mathrm{Vd} \_$Oct $\beta \mathrm{R}$, confirmed the correct identification and classification of these proteins as octopamine receptors in $V$. destructor. It was once thought that amitraz only interacts with octopamine receptors (OAR). However, during that time, tyramine type 1 receptors have been wrongly classified as OAR (Chen et al. 2007). Later, this receptor was classified as Oct/TyrR (Baron et al. 2015) and recently, tyramine type 1 receptor was finally classified as TAR (Farooqui 2012; Finetti et al. 2021). However, as this is a recent change in the classification, it is still not updated in public databases, that maintain erroneous annotations, 
leading to confusion when trying to identify and classify this family of receptors. This is the case of $V$. destructor, in which Vd_TAR1 (XP_02270329) is described as octopamine receptor-like, actually being a tyramine receptor, as we have thoroughly described in this study.

Resistance to amitraz in Varroa have been reported in populations from different locations around the world, such as the USA (Elzen et al. 1999, 2000; Rinkevich 2020), Mexico (Rodríguez-Dehaibes et al. 2005), Argentina (Maggi et al. 2010), the Czech Republic (Kamler et al. 2016) and France (Almecija et al. 2020). In addition to these publications, anecdotal reports of reduced amitraz efficacy are widely discussed among beekeepers (Rinkevich 2020). However, until now, the mechanism causing this lack of efficacy was unknown.

The mechanism of resistance to amitraz has been thoroughly studied in the cattle tick R. microplus (Baxter and Barker 1999; Chen et al. 2007; Corley et al. 2013; Baron et al. 2015; Koh-Tan et al. 2016; Jonsson et al. 2018). In this species, so far, the resistance detected in the field has been associated with polymorphisms in the octopamine and tyramine receptors, suggesting that target site insensitivity is the most common mechanism of resistance to amitraz. However, it is necessary to carry out more investigation to rule out the possible implication of other mechanisms of resistance (i.e. metabolic resistance). Chen et al. (2007) found two amino acid substitutions (T8P and L22S) in the tyramine receptor gene that were only present in American strains highly resistant to amitraz. Further analysis by Baron et al. (2015) supported the association of these two SNPs with the resistance in field samples collected in South Africa. However, previous analysis of the same gene with samples collected in Australia did not find any SNPs differentiating susceptible from resistant strains (Baxter and Barker 1999). In an attempt to address this issue, Corley et al. (2013) widen the scope of the analysis to other octopamine receptors using the same amitraz-resistant Ultimo strain analysed by Baxter and Barker. They found an increased frequency of the mutation I61F in the $\beta$-adrenergic octopamine receptor (RmBAOR) providing circumstantial support for associating this mutation with the resistance to amitraz in the Ultimo strain. Supporting this association, an I45F mutant of Bombyx mori OAR2 (equivalent to I61F in RmBAOR) showed reduced sensitivity to the amitraz metabolite DPMF ( $\mathrm{N}^{2}$-(2,4-Dimethylphenyl)- $\mathrm{N}^{1}$-methyformamidine) in HEK293 cells (Takata et al. 2020). In a different study, cell lines derived from acaricide-resistant $R$. microplus colonies from Colombia contained a $36 \mathrm{bp}$ duplication in the RmBAOR gene leading to a 12 amino acid insertion in the first transmembrane domain of the protein (Koh-Tan et al. 2016). Further analyses of resistant R. microplus from Brazil, Mexico, Australia, Thailand and South Africa supported the association of I61F with the resistance, but also described novel
SNPs in the RmBAOR associated with amitraz resistance in specific populations (Jonsson et al. 2018).

A recent study have suggested that the mechanism of resistance to amitraz in the citrus red mite, Panonychus citri (Acari: Tetranychidae) is associated with the mutation T752C, located at the $5^{\prime}$ untranslated region (UTR) of the $\beta-2 \mathrm{R}$ adrenergic-like octopamine receptor gene (Yu et al. 2021). The mutation resulted in the formation of a short hairpin loop structure in mRNA and gene expression was down-regulated by more than $50 \%$ in the amitraz-resistant strain. They have also showed a significant correlation (94.4\%) between the presence of the mutation and the resistance ratio. This study, along with all mentioned above studying the mechanism of resistance on R. microplus is pointing to the modification of the target site as a major mechanism of resistance to amitraz, at least in Acari. In addition, also supporting the implication of the $\beta-2 \mathrm{R}$ adrenergic-like octopamine receptor in the mechanism of resistance, Guo et al. (2021) have found that this is the only octopamine/tyramine receptor mediating the effect of amitraz in vivo. In this study, they also showed that 3 residues (E208, I335, I350), located in the transmembrane segments TM5, TM6 and TM7 are key for the differential activity of amitraz in A. mellifera and $V$. destructor.

To date, there is no reported association between mutations in $\alpha$-adrenergic octopamine receptors and resistance to amitraz. Therefore, we analysed Vd_TAR1 and Vd_Oct $\beta_{2} \mathrm{R}$, the receptors of $V$. destructor phylogenetically closer to those of $R$. microplus, $P$. citri and A. mellifera reporting polymorphisms associated with amitraz resistance or selectivity between species. None of the mutations described in these species were found in the $V$. destructor samples analysed in this study. However, we did identify two novel non-synonymous substitutions in the $V d \_o c t \beta_{2} r$ gene with a differential geographical distribution. A substitution of asparagine 87 to serine (N87S) associated with treatment failures in France, and a substitution of tyrosine 215 to histidine $(\mathrm{Y} 215 \mathrm{H})$ in samples collected across the USA from colonies reporting low amitraz efficacy. None of the samples analysed in this study were collected as part of a structured sampling strategy designed to elucidate the mechanism of resistance to amitraz. Rather, most of them were part of projects, experiments or surveys conducted to validate previous reports of treatment failures. After a careful case-by-case analysis of the sampling and treatment history, it is possible to draw conclusions on whether these mutations are associated with the resistance to amitraz. In the case of samples collected in France, when the sampling was conducted after finishing the treatment with amitraz (Table 1), a significant number of mites were mutants for N87S (always above 50\%), showing an association with the efficacy observed in the field. On the other hand, the samples collected from colonies not exposed to amitraz at least the year before the sample collection were 
mostly wild-type. This suggests that amitraz is exerting a significant selection pressure, favouring the prevalence of N87S mutants in the populations after an intensive treatment regime for many years. In the USA, the samples were collected as part of different projects and screening efforts using different sampling approaches. In these cases, whenever the mites (phoretic) were collected after finishing the treatment with amitraz (NJ-M-001, NJ-M-002, NJ-M-008, NJ-EP-2) or when the treatment was still ongoing (ORAV01, OR-AV02, MI-22, MI-33), the frequency of mutants was very high (Table S1), indicating an association between the presence of the mutation $\mathrm{Y} 215 \mathrm{H}$ and the survival after exposure. However, the samples collected from other colonies (OR-AL38, OR-AL51, MI-56, MI-58), taking part in the same field assay in Oregon and Michigan but treated with thymol, also showed a high frequency of mutant mites. This may be explained considering that amitraz has been used intensively for long time in these locations. Thus, given the high movement of mites within apiaries (Kulhanek et al. 2021), it is possible that a significant part of the population was already mutant before starting the field trials in 2018 . The historical data gathered after the analysis of samples collected in 2016 and 2017 also support this idea. Our data show that the mutation was nearly absent in the samples collected in several states in 2016, with only one sample with mutants in Michigan (MI-09). Yet, in 2017, although some samples were still completely wild-type, many of them show that the mutation was present in a significant number of mites. Hence, it is reasonable to think that in 2018 , following the same treatment regime with amitraz, the frequency of mutants -e.g. resistant mites- would predominate (Table S1).

The joint analysis of the data also suggests that the resistance have evolved independently at both locations. The mutation N87S was detected only in mites collected in France, while $\mathrm{Y} 215 \mathrm{H}$ was detected only in the mites collected in the USA. This result is yet another example of the capacity of this species to evolve resistance to the same acaricide via multiple independent pathways. This was already described for the resistance to pyrethroids based-acaricides. In Europe mites carry mostly the mutation L925V in the VGSC, while those from the USA carry the mutations L925M and L925I (González-Cabrera et al. 2013, 2016, 2018; Millán-Leiva et al. 2021a). A more recent study also evidenced that this was the result of a parallel and independent evolution process (Millán-Leiva et al. 2021b). Following the same rationale, the different mutations associated with the resistance of $R$. microplus to amitraz that evolved in different locations, in different receptor proteins and also in different residues of the same protein (Chen et al. 2007; Corley et al. 2013; Koh-Tan et al. 2016; Jonsson et al. 2018), are a very good example of the many possibilities that can be found in $V$. destructor. As we have screened a relatively small number of samples, from few locations, a larger screening effort is called for to draw a more accurate and complete picture of the situation.

A thorough in silico analysis of the $\beta$-octopamine receptor of Schistocerca gregaria showed that the nonpolar residues of the transmembrane regions are buried in the receptor core to form a hydrophobic pocket (active pocket) that is closed to the extracellular region and surrounded by the transmembrane domain ( $\mathrm{Lu}$ et al. 2017). According to the in silico model, asparagine 87 is located at the end of helix II of $\mathrm{Vd}_{-}$ Oct $\beta_{2} R$ (Fig. 3), positioned near to the residues predicted as the putative binding site for octopamine. In the N87S mutation, the mutant residue is smaller and more hydrophobic $(\mathrm{N}$ -0.78; S -0.18) (Eisenberg et al. 1984) than the wild-type residue and this might lead to loss of hydrogen bonds and/or disturb the correct folding of the protein. Since this mutation is in a domain that is important for the main activity of the receptor, it might somehow disturb its function. A more targeted study found out that in Sitophilus oryzae amitraz and octopamine might not share the same binding site, although the two sites were close to one another (Braza et al. 2019). Docking of amitraz to $S$. oryzae tyramine receptor showed eight residues of the receptor closely interacting with this ligand. One of these amino acids was Asn91, corresponding to Asn87 in V. destructor. When this position was examined across Acari and other arthropod species, it was found that this residue was totally conserved in both, $\beta$-adrenergic octopamine and tyramine receptors (Fig. 2B and Fig. S1A). On the other hand, in $\alpha$-adrenergic-like octopamine receptors, this position shows a serine residue instead of an asparagine, indicating a possible different interaction of amitraz with Oct $\alpha$ Rs in comparison with Oct $\beta R s$ and TAR1s. Indeed, Kita et al. (2017) showed that the potency of amitraz and its metabolite DPMF to activate $B$. mori octopamine receptors was 347- and 2274-fold higher in $\beta$-adrenergic-like octopamine receptors than in $\alpha$-adrenergic-like octopamine receptors, respectively. Additionally, based on the consensus sequence for $\mathrm{N}$-linked glycosylation (NXT/S), residue N87 is predicted as a putative $\mathrm{N}$-glycosylation site in $\mathrm{Vd}$ _Oct $\beta_{2} \mathrm{R}$. $\mathrm{N}$-glycosylation has been shown to be important for many GPCRs, especially in correct folding, surface expression, signalling, and dimerization (Nørskov-Lauritsen and Bräuner-Osborne 2015; Patwardhan et al. 2021). Actually, it has been reported that $\mathrm{N}$-glycosylation of the $\alpha_{1 \mathrm{D}}$-adrenergic receptor is required for correct trafficking and complete translation of a nascent, functional receptor (Janezic et al. 2020 ), and that the $\mathrm{N}$-glycosylation of the $\beta_{2}$-adrenergic receptor regulates its function by influencing receptor dimerization ( $\mathrm{Li}$ et al. 2017). Therefore, if the asparagine at position 87 of the Vd_Oct $\beta_{2} \mathrm{R}$ is indeed a $\mathrm{N}$-glycosylation site, its substitution for a serine residue may affect the integrity and functionality of this receptor.

The mutation $\mathrm{Y} 215 \mathrm{H}$ is sited in the fifth transmembrane segment of the Vd_Oct $\beta_{2} \mathrm{R}$ (Fig. 4). In this case, the 
wild-type residue is more hydrophobic than the mutant residue (Y 0.26; H -0.4) (Eisenberg et al. 1984). After in silico analysis, the prediction results based on secondary structure showed a negative effect of the substitution (score +50 with SNAP2; 100\% probability of damage with PolyPhen2). The analysis of the tertiary structure of the mutant protein indicated a decrease in the stability (Reliable index: 8 with I-MUTANT), and predicted that the hydrophobic interactions, either in the core of the protein or on the surface, would be lost (HOPE). Therefore, it seems that the change from tyrosine to histidine in this domain of the protein could seriously alter the conformation of the helix and its surroundings, which can affect the interaction of the receptor with the ligand. This hypothesis is supported by the conservation of the tyrosine residue at this position of the protein among all species analysed in this study. (Fig S1B).

Amitraz exerts its acaricidal action as an agonist of octopamine. In invertebrates, octopamine acts as neurotransmitter, neuromodulator, and neurohormone, playing a fundamental role on physiological processes (Farooqui 2007). By binding to G-coupled receptors on the surface of neurons and other cells, octopamine functions as neurotransmitter affecting diverse behaviours such as excitation, aggression and egg laying (Roeder 2005). In ticks, sublethal and behaviour effects of amitraz are considered more important than lethality in the mode of action. It has been shown that amitraz causes hyperactivity, leg waving, detaching behaviour and inhibition of the reproduction (Page 2008). Therefore, the effect of amitraz goes beyond killing like a poison; it is effective by acting as a behaviour disruptor, inhibiting the mites' ability to remain attached to the bees before killing them. This suggests that laboratory bioassays that only measure $\mathrm{LD}_{50}$ may underestimate resistance as it would express under field conditions. Thus, looking for associations between the presence of mutations and the survival of mites in colonies treated under field conditions, is perhaps a more appropriate approach to elucidate the mechanism of resistance to products that cause behavioural changes that result in death, rather than cause death directly.

Our findings supports the association of the mutations $\mathrm{N} 87 \mathrm{~S}$ and $\mathrm{Y} 215 \mathrm{H}$ in the $\beta$-adrenergic-like octopamine receptor of $V$. destructor with the resistance to amitraz reported in the field. Future research is needed to show a causal relationship between these mutations and the evolution of resistance to amitraz, but these tests must account for the behavioural changes induced by amitraz. Moreover, data from functional analysis via electrophysiology and other approaches will help to fully characterise the interaction of amitraz with wild-type and mutant receptors. This studies will provide a clear picture of these mutations' role in the mechanism of resistance. Other approaches should also be conducted in the future to determine whether the presence of these mutations is reducing the reproductive fitness of resistant mites, a very important parameter when designing management strategies.

The current status in the management of $V$. destructor shows (i) a widespread resistance to pyrethroids (Kim et al. 2009; Bak et al. 2012; González-Cabrera et al. 2016, 2018; Kamler et al. 2016; Millán-Leiva et al. 2021a); (ii) increasing cases of failures after treatments with coumaphos (Elzen and Westervelt 2002; Maggi et al. 2009, 2011); (iii) and the overreliance of beekeepers on amitraz (Haber et al. 2019), which may favour the evolution of resistance to this acaricide. In this scenario, monitoring the resistance to acaricidal compounds is crucial to decide whether a given treatment is likely to be successful, as well as to avoid selection pressures with treatments that can lead to an increase of mites carrying mutations conferring resistance. To help on this endeavour, we have developed high throughput allelic discrimination by TaqMan assays for detecting N87S and Y215H mutations in the Vd_Oct $\beta_{2} \mathrm{R}$, as was previously implemented to detect mutations in the $V$. destructor VGSC associated with resistance to pyrethroids (González-Cabrera et al. 2013, 2016). This assay is relatively cheap, fast, robust and capable of accurately genotype individual mites in poor quality samples. Therefore, the implementation of allelic discrimination assays like those described in this study will be especially suited towards determining the distribution and frequency of mutations associated to resistances in local Varroa populations. This information would be very valuable for designing a more rational control of Varroa, selecting each time the best acaricide for the apiaries.

\section{Author contributions}

CSHR and JGC designed research. CSHR, SMM, GA, KC, JDJ, JGC conducted experiments and analysed data. GA, MV, KC, SCC, DvE, contributed biological samples. All contribute to writing the manuscript.

Supplementary Information The online version contains supplementary material available at https://doi.org/10.1007/s10340-021-01471-3.

Acknowledgements The authors thank the Bee Informed Partnership (thanks Dr. Nathalie Steinhauer, and Project Apis m), beekeepers and beekeepers' associations from different countries for providing the mite samples used in this study. Thanks to Klemens Krieger for his support and personal implication at the beginning of this research effort. A previous version of this manuscript was revised by Frank Rinkevich (USDA, Baton Rouge, Louisiana) his comments and suggestions were used to improve the final version.

Funding Open Access funding provided thanks to the CRUE-CSIC agreement with Springer Nature. Joel González-Cabrera was supported by the Spanish Ministry of Economy and Competitiveness, Ramón y Cajal Program (RYC-2013-261 13834). The work at the Universitat de València was funded by the Spanish Ministry of Economy and Competitiveness (grant: CGL2015-65025-R, MINECO/FEDER, UE), Spanish Ministry of Science, Innovation and Universities (grant: 
RTI2018-095120-B-100/FEDER, UE) and the Foundation for Food and Agricultural Research, Washington DC, USA (grant: 552951). Sample collection in the USA was funded by the US National Honey Bee Disease Survey USDA-APHIS (16-8100-1624-CA, 15-8100-1624-CA).

Data availability The datasets generated and analysed during the current study are available within the article and its supplementary materials, as well as from the corresponding author on reasonable request.

\section{Declarations}

Conflict of interest There are no competing interests to declare.

\section{Consent to participate Not applicable.}

Consent for publication All authors consent to the publication of this manuscript in Journal of Pest Science.

Ethical approval This study does not contain any experiments using any animal species that require ethical approval.

Open Access This article is licensed under a Creative Commons Attribution 4.0 International License, which permits use, sharing, adaptation, distribution and reproduction in any medium or format, as long as you give appropriate credit to the original author(s) and the source, provide a link to the Creative Commons licence, and indicate if changes were made. The images or other third party material in this article are included in the article's Creative Commons licence, unless indicated otherwise in a credit line to the material. If material is not included in the article's Creative Commons licence and your intended use is not permitted by statutory regulation or exceeds the permitted use, you will need to obtain permission directly from the copyright holder. To view a copy of this licence, visit http://creativecommons.org/licenses/by/4.0/.

\section{References}

Adzhubei IA et al (2010) A method and server for predicting damaging missense mutations. Nat Methods 7:248-249. https://doi.org/10. 1038/nmeth0410-248

Afonina I, Zivarts M, Kutyavin I, Lukhtanov E, Gamper H, Meyer R (1997) Efficient priming of PCR with short oligonucleotides conjugated to a minor groove binder. Nucleic Acids Res 25:26572660. https://doi.org/10.1093/nar/25.13.2657

Almecija G, Poirot B, Cochard P, Suppo C (2020) Inventory of Varroa destructor susceptibility to amitraz and tau-fluvalinate in France. Exp Appl Acarol. https://doi.org/10.1007/s10493-020-00535-w

Aronstein KA, Saldivar E, Vega R, Westmiller S, Douglas AE (2012) How Varroa parasitism affects the immunological and nutritional status of the honey bee, Apis mellifera. Insects 3:601-615. https:// doi.org/10.3390/insects3030601

Bak B, Wilde J, Siuda M (2012) Characteristics of north-eastern population of Varroa destructor resistant to synthetic pyrethroids. Med Weter 68:603-606

Baron S, van der Merwe NA, Madder M, Maritz-Olivier C (2015) SNP analysis infers that recombination is involved in the evolution of amitraz resistance in Rhipicephalus microplus. PLoS ONE 10:e0131341. https://doi.org/10.1371/journal.pone.01313 41

Baxter GD, Barker SC (1999) Isolation of a cDNA for an octopaminelike, G-protein coupled receptor from the cattle tick, Boophilus microplus. Insect Biochem Mol Biol 29:461-467. https://doi.org/ 10.1016/S0965-1748(99)00023-5

Beaurepaire AL, Truong TA, Fajardo AC, Dinh TQ, Cervancia C, Moritz RF (2015) Host specificity in the honeybee parasitic mite, Varroa spp. in Apis mellifera and Apis cerana. Plos One 10:e0135103. https://doi.org/10.1371/journal.pone.0135103

Boecking O, Genersch E (2008) Varroosis - the ongoing crisis in bee keeping. J Consum Protect Food Safety 3:221-228. https://doi. org/10.1007/s00003-008-0331-y

Bonzini S, Tremolada P, Bernardinelli I, Colombo M, Vighi M (2011) Predicting pesticide fate in the hive (part 1): experimentally determined $\tau$-fluvalinate residues in bees, honey and wax. Apidologie 42:378-390. https://doi.org/10.1007/s13592-011-0011-2

Braza MKE, Gazmen JDN, Yu ET, Nellas RB (2019) Ligandinduced conformational dynamics of a tyramine receptor from Sitophilus oryzae. Sci Rep 9:16275. https://doi.org/10.1038/ s41598-019-52478-x

Calatayud-Vernich P, Calatayud F, Simó E, Picó Y (2018) Pesticide residues in honey bees, pollen and beeswax: assessing beehive exposure. Environ Pollut 241:106-114. https://doi.org/10.1016/j. envpol.2018.05.062

Chen AC, He H, Davey RB (2007) Mutations in a putative octopamine receptor gene in amitraz-resistant cattle ticks. Vet Parasitol 148:379-383. https://doi.org/10.1016/j.vetpar.2007.06.026

Corley SW, Jonsson NN, Piper EK, Cutulle C, Stear MJ, Seddon JM (2013) Mutation in the RmbetaAOR gene is associated with amitraz resistance in the cattle tick Rhipicephalus microplus. Proc Natl Acad Sci U S A 110:16772-16777. https://doi.org/10.1073/ pnas. 1309072110

Desneux N, Decourtye A, Delpuech JM (2007) The sublethal effects of pesticides on beneficial arthropods. Annu Rev Entomol 52:81106. https://doi.org/10.1146/annurev.ento.52.110405.091440

Dietemann V et al. (2013) Standard methods for varroa research. In: Dietemann V, Ellis JD, Neumann P (eds) The COLOSS BEEBOOK, Volume II: standard methods for Apis mellifera pest and pathogen research. Journal of Apicultural Research, 52(1), https:// doi.org/10.3896/IBRA.1.52.1.09

Eisenberg D, Schwarz E, Komaromy M, Wall R (1984) Analysis of membrane and surface protein sequences with the hydrophobic moment plot. J Mol Biol 179:125-142. https://doi.org/10.1016/ 0022-2836(84)90309-7

Elzen PJ, Baxter JR, Spivak M, Wilson WT (1999) Amitraz resistance in varroa: new discovery in North America. Am Bee J 139:362-362

Elzen PJ, Baxter JR, Spivak M, Wilson WT (2000) Control of Varroa jacobsoni Oud. resistant to fluvalinate and amitraz using coumaphos. Apidologie 31:437-441. https://doi.org/10.1051/apido: 2000134

Elzen PJ, Eischen FA, Baxter JB, Pettis J, Elzen GW, Wilson WT (1998) Fluvalinate resistance in Varroa jacobsoni from several geographic locations. Am Bee J 138:674-676

Elzen PJ, Westervelt D (2002) Detection of coumaphos resistance in Varroa destructor in Florida. Am Bee J 142:291-292. https://doi. org/10.1051/apido:2004036

EMA (2010) Guideline on veterinary medicinal products controlling Varroa destructor parasitosis in bees. https://www.ema. europa.eu/en/documents/scientific-guideline/guideline-veter inary-medicinal-products-controlling-varroa-destructor-paras itosis-bees_en.pdf. Accessed 16 July 2021

Farooqui T (2007) Octopamine-mediated neuromodulation of insect senses. Neurochem Res 32:1511-1529. https://doi.org/10.1007/ s11064-007-9344-7

Farooqui T (2012) Review of octopamine in insect nervous systems. Open Access Insect Physiol. https://doi.org/10.2147/oaip. S20911 
Feyereisen R, Dermauw W, Van Leeuwen T (2015) Genotype to phenotype, the molecular and physiological dimensions of resistance in arthropods. Pestic Biochem Physiol 121:61-77. https:// doi.org/10.1016/j.pestbp.2015.01.004

Filipek S (2019) Molecular switches in GPCRs. Curr Opin Struct Biol 55:114-120. https://doi.org/10.1016/j.sbi.2019.03.017

Finetti L, Roeder T, Calo G, Bernacchia G (2021) The insect type 1 tyramine receptors: from structure to behavior. Insects. https:// doi.org/10.3390/insects12040315

González-Cabrera J et al (2018) A single mutation is driving resistance to pyrethroids in European populations of the parasitic mite, Varroa destructor. J Pest Sci 91:1137-1144. https://doi. org/10.1007/s10340-018-0968-y

González-Cabrera J, Davies TGE, Field LM, Kennedy PJ, Williamson MS (2013) An amino acid substitution (L925V) associated with resistance to pyrethroids in Varroa destructor. PLoS ONE 8:e82941. https://doi.org/10.1371/journal.pone.0082941

González-Cabrera J et al (2016) Novel Mutations in the voltage-gated sodium channel of pyrethroid-resistant Varroa destructor populations from the Southeastern USA. PLoS ONE 11:e0155332. https://doi.org/10.1371/journal.pone.0155332

Gracia-Salinas MJ, Ferrer-Dufol M, Latorre-Castro E, MoneroManera C, Castillo-Hernández JA, Lucientes-Curd J, PeribanezLópez MA (2006) Detection of fluvalinate resistance in Varroa destructor in Spanish apiaries. J Apicult Res 45:101-105

Guo L, Fan X, Qiao X, Montell C, Huang J (2021) An octopamine receptor confers selective toxicity of amitraz on honeybees and Varroa mites. Elife

Haber AI, Steinhauer NA, vanEngelsdorp D (2019) Use of chemical and nonchemical methods for the control of Varroa destructor (Acari: Varroidae) and associated winter colony losses in U.S. beekeeping operations. J Econ Entomol 112:1509-1525. https:// doi.org/10.1093/jee/toz088

Harrison IR, Kozlik A, McCarthy JF, Palmer BH, Wakerley SB, Watkins TI, Weighton DM (1972) 1,5-di-(2,4-dimethylphenyl)3-methyl-1,3,5-triazapenta-1,4-diene, a new acaricide active against strains of mites resistant to organophosphorus and bridged diphenyl compounds. Pestic Sci 3:679-680. https:// doi.org/10.1002/ps.2780030603

Hecht M, Bromberg Y, Rost B (2015) Better prediction of functional effects for sequence variants. BMC Genom 16:S1. https://doi. org/10.1186/1471-2164-16-S8-S1

Hollingworth RM, Lund AE (1982) Biological and neurotoxic effects of amidine pesticides. In: Coats JR (ed) Insecticide mode of action. Academic Press, New York, pp 198-227

Hubert J, Nesvorna M, Kamler M, Kopecky J, Tyl J, Titera D, Stara $\mathrm{J}$ (2014) Point mutations in the sodium channel gene conferring tau-fluvalinate resistance in Varroa destructor. Pest Manag Sci 70:889-894. https://doi.org/10.1002/ps.3679

Janezic EM et al (2020) N-glycosylation of alpha1D-adrenergic receptor $\mathrm{N}$-terminal domain is required for correct trafficking, function, and biogenesis. Sci Rep 10:7209. https://doi.org/10. 1038/s41598-020-64102-4

Jonsson NN, Klafke G, Corley SW, Tidwell J, Berry CM, Koh-Tan HC (2018) Molecular biology of amitraz resistance in cattle ticks of the genus Rhipicephalus. Front Biosci (landmark Ed) 23:796-810. https://doi.org/10.2741/4617

Kall L, Krogh A, Sonnhammer EL (2004) A combined transmembrane topology and signal peptide prediction method. J Mol Biol 338:1027-1036. https://doi.org/10.1016/j.jmb.2004.03.016

Kamler M, Nesvorna M, Stara J, Erban T, Hubert J (2016) Comparison of tau-fluvalinate, acrinathrin, and amitraz effects on susceptible and resistant populations of Varroa destructor in a vial test. Exp Appl Acarol 69:1-9. https://doi.org/10.1007/s10493-016-0023-8

Kearse $M$ et al (2012) Geneious Basic: an integrated and extendable desktop software platform for the organization and analysis of sequence data. Bioinformatics 28:1647-1649. https://doi.org/10. 1093/bioinformatics/bts 199

Kim W et al (2009) A geographical polymorphism in a Voltage-Gated Sodium Channel gene in the mite, Varroa destructor, from Korea. Korean J Apicult 24:159-165

Kita $\mathrm{T}$ et al (2017) Amitraz and its metabolite differentially activate alpha- and beta-adrenergic-like octopamine receptors. Pest Manag Sci 73:984-990. https://doi.org/10.1002/ps.4412

Koh-Tan HH, Strachan E, Cooper K, Bell-Sakyi L, Jonsson NN (2016) Identification of a novel beta-adrenergic octopamine receptorlike gene (betaAOR-like) and increased ATP-binding cassette B10 (ABCB10) expression in a Rhipicephalus microplus cell line derived from acaricide-resistant ticks. Parasit Vectors 9:425. https://doi.org/10.1186/s13071-016-1708-x

Kulhanek K, Garavito A, vanEngelsdorp D (2021) Accelerated Varroa destructor population growth in honey bee (Apis mellifera) colonies is associated with visitation from non-natal bees. Sci Rep 11:7092. https://doi.org/10.1038/s41598-021-86558-8

Kumar R (2019) Molecular markers and their application in the monitoring of acaricide resistance in Rhipicephalus microplus. Exp Appl Acarol 78:149-172. https://doi.org/10.1007/ s10493-019-00394-0

Li X, Zhou M, Huang W, Yang H (2017) N-glycosylation of the beta2 adrenergic receptor regulates receptor function by modulating dimerization. FEBS J 284:2004-2018. https://doi.org/10.1111/ febs. 14098

Liu N, Li T, Wang Y, Liu S (2021) G-protein coupled receptors (GPCRs) in insects-A potential target for new insecticide development. Molecules. https://doi.org/10.3390/molecules26102993

Lu HM et al (2017) Ligand-binding characterization of simulated betaadrenergic-like octopamine receptor in Schistocerca gregaria via progressive structure simulation. J Mol Graph Model 77:25-32. https://doi.org/10.1016/j.jmgm.2017.07.025

Maggi MD, Ruffinengo SR, Damiani N, Sardella NH, Eguaras MJ (2009) First detection of Varroa destructor resistance to coumaphos in Argentina. Exp Appl Acarol 47:317-320. https://doi. org/10.1007/s10493-008-9216-0

Maggi MD, Ruffinengo SR, Mendoza Y, Ojeda P, Ramallo G, Floris I, Eguaras MJ (2011) Susceptibility of Varroa destructor (Acari: Varroidae) to synthetic acaricides in Uruguay: Varroa mites' potential to develop acaricide resistance. Parasitol Res 108:815821. https://doi.org/10.1007/s00436-010-2122-5

Maggi MD, Ruffinengo SR, Negri P, Eguaras MJ (2010) Resistance phenomena to amitraz from populations of the ectoparasitic mite Varroa destructor of Argentina. Parasitol Res 107:1189-1192. https://doi.org/10.1007/s00436-010-1986-8

Marsh L (2015) Strong ligand-protein interactions derived from diffuse ligand interactions with loose binding sites. Biomed Res Int 2015:746980. https://doi.org/10.1155/2015/746980

Martin S, Hogarth A, Van Breda J, Perrett J (1998) A scientific note on Varroa jacobsoni Oudemans and the collapse of Apis mellifera $\mathrm{L}$. colonies in the United Kingdom. Apidologie 29:369-370. https:// doi.org/10.1051/apido:19980407

Medici SK, Maggi MD, Sarlo EG, Ruffinengo S, Marioli JM, Eguaras MJ (2016) The presence of synthetic acaricides in beeswax and its influence on the development of resistance in Varroa destructor. J Apicult Res 54:267-274. https://doi.org/10.1080/00218839. 2016.1145407

Milani N (1995) The resistance of Varroa-Jacobsoni Oud to pyrethroids-A laboratory assay. Apidologie 26:415-429

Milani N, Della Vedova G (2002) Decline in the proportion of mites resistant to fluvalinate in a population of Varroa destructor not treated with pyrethroids. Apidologie 33:417-422. https://doi.org/ 10.1051/apido:2002028

Millán-Leiva A, Marín O, Christmon K, vanEngelsdorp D, GonzálezCabrera J (2021a) Mutations associated with pyrethroid resistance 
in Varroa mite, a parasite of honey bees, are widespread across the United States. Pest Manag Sci 77:3241-3249. https://doi.org/ $10.1002 /$ ps.6366

Millán-Leiva A et al (2021b) Mutations associated with pyrethroid resistance in the honey bee parasite Varroa destructor evolved as a series of parallel and sequential events. J Pest Sci 94:1505-1517. https://doi.org/10.1007/s10340-020-01321-8

Mitton GA et al (2018) Varroa destructor: when reversion to coumaphos resistance does not happen. J Apicult Res 57:536-540. https://doi.org/10.1080/00218839.2018.1475038

Mozes-Koch R, Slabezki Y, Efrat H, Kalev H, Kamer Y, Yakobson BA, Dag A (2000) First detection in Israel of fluvalinate resistance in the varroa mite using bioassay and biochemical methods. Exp Appl Acarol 24:35-43. https://doi.org/10.1023/A:1006379114942

Nørskov-Lauritsen L, Bräuner-Osborne H (2015) Role of post-translational modifications on structure, function and pharmacology of class C G protein-coupled receptors. Eur J Pharmacol 763:233240. https://doi.org/10.1016/j.ejphar.2015.05.015

Omasits U, Ahrens CH, Muller S, Wollscheid B (2014) Protter: interactive protein feature visualization and integration with experimental proteomic data. Bioinformatics 30:884-886. https://doi.org/ 10.1093/bioinformatics/btt607

Page SW (2008) Antiparasitic drugs. In: Maddison JE, Page SW, Church DB (eds) Small animal clinical pharmacology, 2nd edn. W.B, Saunders, Edinburgh, pp 198-260

Patwardhan A, Cheng N, Trejo J (2021) Post-translational modifications of $\mathrm{G}$ protein-coupled receptors control cellular signaling dynamics in space and time. Pharmacol Rev 73:120-151. https:// doi.org/10.1124/pharmrev.120.000082

Rader AJ, Anderson G, Isin B, Khorana HG, Bahar I, Klein-Seetharaman J (2004) Identification of core amino acids stabilizing rhodopsin. Proc Natl Acad Sci U S A 101:7246-7251. https://doi.org/ 10.1073/pnas.0401429101

Ramsey SD et al (2019) Varroa destructor feeds primarily on honey bee fat body tissue and not hemolymph. Proc Natl Acad Sci U S A 116:1792-1801. https://doi.org/10.1073/pnas.1818371116

Rinkevich FD (2020) Detection of amitraz resistance and reduced treatment efficacy in the Varroa Mite, Varroa destructor, within commercial beekeeping operations. PLoS ONE 15:e0227264. https:// doi.org/10.1371/journal.pone.0227264

Rodríguez-Dehaibes SR, Otero-Colina G, Sedas VP, Jiménez JAV (2005) Resistance to amitraz and flumethrin in Varroa destructor populations from Veracruz, Mexico. J Apicult Res 44:124-125. https://doi.org/10.1080/00218839.2005.11101162

Roeder T (2005) Tyramine and octopamine: ruling behavior and metabolism. Annu Rev Entomol 50:447-477. https://doi.org/10.1146/ annurev.ento.50.071803.130404
Rosenkranz P, Aumeier P, Ziegelmann B (2010) Biology and control of Varroa destructor. J Invertebr Pathol 103:S96-S119. https:// doi.org/10.1016/j.jip.2009.07.016

Sammataro D, Untalan P, Guerrero F, Finley J (2005) The resistance of varroa mites (Acari: Varroidae) to acaricides and the presence of esterase. Int J Acarol 31:67-74

Solignac M et al (2005) The invasive Korea and Japan types of Varroa destructor, ectoparasitic mites of the Western honeybee (Apis mellifera), are two partly isolated clones. Proc Royal Soc B-Biol Sci 272:411-419. https://doi.org/10.1098/rspb.2004.2853

Steinhauer N, Kulhanek K, Antunez K, Human H, Chantawannakul P, Chauzat MP, vanEngelsdorp D (2018) Drivers of colony losses. Curr Opin Insect Sci 26:142-148. https://doi.org/10.1016/j.cois. 2018.02.004

Techer MA et al (2019) Divergent evolutionary trajectories following speciation in two ectoparasitic honey bee mites. Commun Biol 2:357. https://doi.org/10.1038/s42003-019-0606-0

Traynor KS et al (2020) Varroa destructor: a complex parasite, crippling honey bees worldwide. Trends Parasitol 36:592-606. https:// doi.org/10.1016/j.pt.2020.04.004

Venselaar H, te Beek TAH, Kuipers RKP, Hekkelman ML, Vriend G (2010) Protein structure analysis of mutations causing inheritable diseases. An e-Science approach with life scientist friendly interfaces. BMC Bioinform 11:548. https://doi.org/10.1186/ 1471-2105-11-548

Vlogiannitis S et al (2021) Reduced proinsecticide activation by cytochrome $\mathrm{P} 450$ confers coumaphos resistance in the major bee parasite Varroa destructor. Proc Natl Acad Sci U S A. https://doi. org/10.1073/pnas.2020380118

Yang J, Zhang Y (2015) I-TASSER server: new development for protein structure and function predictions. Nucleic Acids Res 43:W174-181. https://doi.org/10.1093/nar/gkv342

Yu SJ et al (2021) Whole genome sequencing and bulked segregant analysis suggest a new mechanism of amitraz resistance in the citrus red mite, Panonychus citri (Acari: Tetranychidae). Pest Manag Sci 77:5032-5048. https://doi.org/10.1002/ps.6544

Zhang D, Zhao Q, Wu B (2015) Structural studies of G protein-coupled receptors. Mol Cells 38:836-842. https://doi.org/10.14348/molce 1ls.2015.0263

Publisher's Note Springer Nature remains neutral with regard to jurisdictional claims in published maps and institutional affiliations. 